\title{
Oncostatin M Confers Neuroprotection against Ischemic Stroke
}

\author{
Sen Guo, ${ }^{1 \star}$ Zuo-Zhi Li, ${ }^{2,3 \star}$ Jun Gong, ${ }^{1,4 \star}$ Mei Xiang, ${ }^{1}$ Peng Zhang, ${ }^{1}$ Guang-Nian Zhao, ${ }^{1}$ Mingchang Li, ${ }^{5}$ Ankang Zheng, ${ }^{1}$ \\ Xueyong Zhu, ${ }^{1}$ Hao Lei, ${ }^{6}$ Tanaka Minoru, ${ }^{7}$ and Hongliang $\mathrm{Li}^{1,8}$ \\ ${ }^{1}$ Department of Cardiology, Renmin Hospital of Wuhan University, Wuhan 430060, PR China, ${ }^{2}$ Department of Cardiology, Peking Union Medical College \\ Hospital, Peking Union Medical College \& Chinese Academy of Medical Sciences, Beijing 100730, PR China, ${ }^{3}$ National Laboratory of Medical Molecular \\ Biology, Institute of Basic Medical Sciences, Chinese Academy of Medical Sciences and Peking Union Medical College, Beijing 100005, PR China, ${ }^{4}$ College of \\ Life Sciences, Wuhan University, Wuhan 430072, PR China, ${ }^{5}$ Department of Neurosurgery, Renmin Hospital of Wuhan University, Wuhan 430060, PR \\ China, ${ }^{6}$ Wuhan Center for Magnetic Resonance, State Key Laboratory of Magnetic Resonance and Atomic and Molecular Physics, Wuhan Institute of \\ Physics and Mathematics, Chinese Academy of Sciences, Wuhan 430060, PR China, ${ }^{7}$ Institute of Molecular and Cellular Biosciences, University of Tokyo, \\ Tokyo 113-0032, Japan, and ${ }^{8}$ Animal Experiment Center/Animal Biosafety Level-III Laboratory, Wuhan University, Wuhan 430060, PR China
}

Cell-surface receptors provide potential targets for the translation of bench-side findings into therapeutic strategies; however, this approach for the treatment of stroke is disappointing, at least partially due to an incomplete understanding of the targeted factors. Previous studies of oncostatin M (OSM), a member of the gp130 cytokine family, have been limited, as mouse models alone may not strongly resemble the human condition enough. In addition, the precise function of OSM in the CNS remains unclear. Here, we report that human OSM is neuroprotective in vivo and in vitro by recruiting OSMR $\beta$ in the setting of ischemic stroke. Using gain- and loss-offunction approaches, we demonstrated that decreased neuronal OSMR $\beta$ expression results in deteriorated stroke outcomes but that $O S M R \boldsymbol{\beta}$ overexpression in neurons is cerebroprotective. Moreover, administering recombinant human OSM to mice before the onset of $\mathrm{I} / \mathrm{R}$ showed that human OSM can be protective in rodent models of ischemic stroke. Mechanistically, OSM/OSMR $\beta$ activate the JAK2/ STAT3 prosurvival signaling pathway. Collectively, these data support that human OSM may represent a promising drug candidate for stroke treatment.

Key words: cerebral ischemia; gene therapy; neuroprotection; OSM; OSMR $\beta$

Significance Statement

OSM, a member of the gp130 cytokine family, regulates neuronal function and survival. OSM engages a second receptor, either LIFR $\alpha$ or OSMR $\beta$, before recruiting gp 130. However, it is not clear whether OSM/OSMR $\beta$ signaling is involved in neuroprotection in the setting of ischemic stroke. Recent studies show that, compared with mouse disease models, the OSM receptor system in rats more closely resembles that in humans. In the present study, we use genetic manipulations of OSMR $\beta$ in both mouse and rat stroke models to demonstrate that OSMR $\beta$ in neurons is critical for neuronal survival during cerebral ischemic/reperfusion. Interestingly, administration of human OSM also leads to improved stroke outcomes. Therefore, OSM may represent a promising drug candidate for stroke treatment.

\section{Introduction}

Stroke is a debilitating disease that leads to mortality and permanent disability of millions of people globally. Treating this dis- ease, however, is a race against time. The therapeutic window to reestablish cerebral blood flow using tissue plasminogen activator, a standard of care available for revascularization, is limited to $4.5 \mathrm{~h}$. Thus, there is an unmet demand for a therapy that reduces

The authors declare no competing financial interests.

*S.G., Z.-Z.L., and J.G. contributed equally to this work.

Correspondence should be addressed to Dr. Hongliang Li, Department of Cardiology, Renmin Hospital of Wuhan University, Animal Experiment Center/Animal Biosafety Level-III Laboratory, Wuhan University, Jiefang Road 238 Wuhan 430060, PR China. E-mail: lih@@whu.edu.cn.

DOI:10.1523/JNEUROSCI.1800-15.2015

Copyright $\odot 2015$ the authors $\quad 0270-6474 / 15 / 3512047-16 \$ 15.00 / 0$ 
cerebral damage (Lo et al., 2003; Moskowitz et al., 2010). Therapeutic agents that target cell-surface receptors represent the largest group of drugs available in the global market (Christopoulos, 2002). Translation of these targets into drugs involves an insightful understanding of the selected therapeutic target. For instance, the stroke-induced activation of NMDA receptors (NMDARs) results in excessive $\mathrm{Ca}^{2+}$ influx and subsequent neuronal death. The use of NMDA receptor blockers, however, may exacerbate stroke outcome (Albers et al., 2001; Lees et al., 2001). Recent studies have suggested that the activation of NMDAR subunit NR2A facilitates neuronal survival, whereas the activation of another NMDAR subunit, NR2B, exerts the opposite effects (Liu et al., 2007). Thus, substantial insight into the precise biological functions of the selected therapeutic targets may provide the information needed to design potentially effective drugs that rescue viable cerebral tissues in poststroke patients.

Oncostatin M (OSM), although initially recognized as a growth regulator in A375 melanoma, is a member of the gp 130 (or IL-6/LIFR) cytokine family. OSM engages a second receptor, either leukemia inhibitory factor receptor $\alpha(\operatorname{LIFR} \alpha)$ or OSM receptor $\beta$ chain (OSMR $\beta$ ), before recruiting gp130 (Gearing et al., 1992). Previous studies primarily focused on the role of OSM in inflammation, cell proliferation, and hematopoiesis (Hui et al., 1997; Gazel et al., 2006). Importantly, increasing evidence shows that OSM is also involved in pathological conditions in nervous system. For instance, Morikawa (2005) indicated that, after sciatic nerve axotomy, the number of OSMR $\beta$-positive neurons on the injured side was significantly decreased. Moreover, OSM reduces NMDA-induced neuronal death and inhibits excitotoxic injury in vivo (Weiss et al., 2006). A more recent study showed that OSM treatment reduces lesion size and improves functional recover and neurite outgrowth after spinal cord hemisection (Slaets et al., 2014). Several transcription factors activated by OSM/gp130, specifically signal transducer and activator of transcription-3 (STAT3) and mitogen-activated protein kinase (MAPK), determine the fate of neurons in the setting of various stimuli (Oliva et al., 2012). Notably, the physiological role of OSM in neuronal survival remains occasionally controversial. For example, OSM derived from mononuclear cells induces the apoptosis of primary neurons (Ensoli et al., 1999). The contradictory roles of OSM in the regulation of cell survival may be attributable to the differences in experimental settings, cell types, stimuli, and more importantly differential recruitment of receptors. Indeed, Tanaka et al. (2010) recently showed that mutation of OSMR $\beta$ in keratinocytes resulted in apoptosis and cell death in the superficial dermis. However, whether OSMR $\beta$ is also required for OSM-mediated neuroprotection during ischemic stroke is unclear. Notably, mouse OSM binds to only OSMR $\beta$ / gp130 in mice, whereas human OSM (hOSM) recruits both OSMR $\beta$ and LIFR $\alpha$ in rats and humans. Thus, using rat models may more strongly replicate the functions of human-derived OSM in vivo.

The present study revealed that human OSM serves as a promising therapeutic agent that protects against ischemia/reperfusion (I/R)-induced cerebral injury. Using a combination of mouse and rat middle cerebral artery occlusion (MCAO) stroke models, we elucidated that OSM recruits OSMR $\beta$ during ischemic stroke. Mechanistically, this activates the JAK2/STAT3 prosurvival signaling pathway in neurons. Thus, targeting OSM function may be considered a feasible therapeutic strategy for stroke treatment.

\section{Materials and Methods}

Animals. All experiments with animals were approved by the Animal Care and Use Committee of Renmin Hospital of Wuhan University. The OMSR-KO (C57BL/6J background) mice were purchased from RIKEN BioResource Center (RBRC 02711). Neuron-specific Cre transgenic mice (CaMKII $\alpha$-Cre; stock \#005359) and STAT3 conditional ( floxed) mutant mice (STAT3 ${ }^{\text {flox } / \text { flox }}$; stock $\# 016923$ ) were purchased from the The Jackson Laboratory. Full-length mouse OSMR $\beta$ cDNA was inserted after a $p C A G-C A T$ promoter expressing the chloramphenicol acetyltransferase (CAT) gene, which was flanked by loxP sites. The $p C A G-C A T-O S M R \beta$ construct was microinjected into fertilized embryos (C57BL/6J background) to produce OSMR-floxed mice. Then, neuron-specific $O S M R \beta$ transgenic (OSMR-TG) mice were generated by crossing OSMR-floxed mice with CaMKII $\alpha$-Cre mice, and neuron-specific STAT3 knock-out (STAT3-KO) mice were produced by mating STAT3 $3^{\text {flox } f l o x}$ mice with CaMKII $\alpha$-Cre mice. The neuron-specific STAT3 transgenic (STAT3-TG) mice were generated using similar procedures to those used to generate the OSMR-TG mice, and the primers used for genotyping were as follows: CAG forward, 5'-CCCCCTGAACC TGAAACATA-3'; and Stat3C reverse, 5'-GCAATCTCCATTGGCTT CTC-3'. OSMR $\beta$ knock-out $(O S M R-K O)$ mice were crossed with STAT3-TG mice to obtain OSMR-KO/STAT3-TG (OKST) mice. OSMRTG/STAT3-KO (OTSK) mice were then produced by crossing OSMR-TG mice with STAT3-KO mice. Only 11- to 12-week-old (25-30 g) male mice were used in this study.

Sprague Dawley (SD) rats were purchased from the Vital River (strain code: 101). The OSMR-KO rat line was created using transcriptional activator-like effector nuclease (TALEN) technology, as previously described (Cermak et al., 2011). The TALEN targeting exon 2 of the $O S M R \beta$ gene was designed using the Targeter Designer (https://tale-nt. cac.cornell.edu/node/add/talen-old) and was assembled using the "Unit Assembly" method. The TALEN expression plasmids were linearized using the restriction endonuclease PmeI (R0560L, NEB) and were then transcribed and tailed using the mMessage mMachine T7 Ultra Kit (AM1345; Ambion). The mature mRNAs were purified using the RNeasy Mini Kit (\#74104, QIAGEN) according to the manufacturer's instructions and then diluted in injection buffer $(10 \mathrm{~mm}$ Tris- $\mathrm{HCl} / 0.1 \mathrm{~mm}$ EDTA, pH 7.4) to a final concentration of $10 \mathrm{ng} / \mu \mathrm{l}$ mRNA per TALEN arm. The mixture $(2 \mathrm{pl})$ was injected into the cytoplasm of one-cell-stage embryos under standard conditions, and the embryos were transferred to a pseudo-pregnant female SD rat, from which viable pups were obtained. A portion of the OSMR $\beta$ gene spanning the TALEN target site was amplified via PCR using the following primers: forward, $5^{\prime}$-GGTCTTAAT TTCTTCCTCGGCTG-3'; and reverse, 5'-ACACGGGATGCAATTG TTTGG-3'. PCR products or T-A colonies cloned from the PCR products were sequenced to detect editing events. The primers (forward, 5'-TGTTTTTGGTCTTTCAGTCTTGG-3'; and reverse, 5'-AAGGTT GGGACAGTCCATTC- $3^{\prime}$ ) were used to genotype the F1 and F2 offspring. Only adult male rats $(250-300 \mathrm{~g})$ were used in this study.

All of the animals were housed in an environment with fixed light (12 $\mathrm{h}$ light/dark cycle), temperature and humidity as well as freely accessible food and water. The experimenters were blinded to the genotypes of the animals.

Administration of hOSM in vivo and in vitro. Recombinant $h O S M$ (295-OM-050; R\&D Systems) was reconstituted at $100 \mu \mathrm{g} / \mathrm{ml}$ in sterile PBS and was intracerebrally injected into wild-type (WT) and OSMR-KO mice $1 \mathrm{~h}$ before the onset of MCAO at a dose of $1 \mu \mathrm{g}$. For the in vitro experiments, cultured neurons transfected with AdshRNA or AdshRNA were treated with $h O S M(100 \mathrm{ng} / \mathrm{ml})$ before in vitro oxygen and glucose deprivation (OGD)/reperfusion treatment.

Focal cerebral ischemia/reperfusion model. Focal cerebral ischemia was induced by transiently occluding the left middle cerebral artery (MCA) as previously described (Lu et al., 2013; Chen et al., 2014; Guo et al., 2014; Xiang et al., 2014). In brief, experimental mice or rats were anesthetized using $2.5 \%-3 \%$ isoflurane in $\mathrm{O}_{2}$. The rectal temperature was maintained at $37 \pm 0.5^{\circ} \mathrm{C}$ using a heating plate. The left common, internal and external carotid arteries were then exposed, followed by the insertion of a 6-0 (for mice, Doccol) or 4-0 silicon-coated monofilament (for rats, 
Doccol) into the internal carotid artery through the external carotid artery. The filament was advanced into the cerebral arterial circle to obstruct the origin of the MCA. The reduction in regional cerebral blood flow (rCBF) was monitored via Doppler analysis (Periflux System 5010; Perimed). After $45 \mathrm{~min}$ (for mice) or $90 \mathrm{~min}$ (for rats), the filament was withdrawn, and the restoration of $\mathrm{rCBF}(>70 \%$ of the basal CBF within $10 \mathrm{~min}$ ) confirmed reperfusion of the MCA territory. For the sham controls, the filament was withdrawn immediately after the CBF was diminished. The animals were returned to an incubator for $2 \mathrm{~h}$ to recover and were provided with free access to food and water.

India ink staining. India ink staining was performed to validate the integrity of the cerebral vasculature, as described previously (Lu et al., 2013; Chen et al., 2014). Briefly, the anesthetized mice were transcardially perfused with $2 \mathrm{ml}$ of preheated staining solution containing $10 \%(\mathrm{w} / \mathrm{v})$ gelatin (Amresco) and 50\% (v/v) India ink (Solarbio). Once the tongues, lips, and gums turned black, a sign of successful staining, we isolated the entire brain and immersed it in $10 \%$ buffered formalin for $24 \mathrm{~h}$. A Nikon D700 digital camera (Nikon) was used to visualize the integrity of the circle of Willis and of its branches.

Neurological deficit scores. At 24 and $72 \mathrm{~h}$ after I/R, the neurological deficits of the mice and the rats were assessed (Wang et al., 2012; Lu et al., 2013; Chen et al., 2014). The following 9 point scale was used for the mice: 0 = absence of neurological deficits; $1=$ left forelimb flexion upon suspension by the tail or failure to fully extend the right forepaw; $2=$ left shoulder adduction upon suspension by the tail; $3=$ reduced resistance to a lateral push toward the left; $4=$ spontaneous movement in all directions with circling to the left only if pulled by the tail; $5=$ circling or walking spontaneously only to the left; $6=$ walking only when stimulated; $7=$ no response to stimulation; and $8=$ stroke-related death. The following 6 point scale was used for the rats: $0=$ absence of neurological deficit; 1 = failure to extend the paretic forepaw; 2 = decreased grip strength of the paretic forepaw; 3 = circling toward the paretic side when pulling the tail; $4=$ spontaneous contralateral circling; and $5=$ strokerelated death.

Quantification of the infarct volume. At 24 or $72 \mathrm{~h}$ after MCAO, the mice or rats were killed, and their brains were immediately removed and sliced into seven consecutive coronal sections; each slice was $1 \mathrm{~mm}$ thick for the mice and $2 \mathrm{~mm}$ thick for the rats. The sections were incubated in 2,3,5-triphenyl-2H-tetrazolium chloride (TTC) staining solution for 15 min (mice) or $30 \mathrm{~min}$ (rats) at $37^{\circ} \mathrm{C}$ and then fixed in $10 \%$ formalin solution overnight. The sections were photographed using a Nikon D700 digital camera and were analyzed using Image-Pro Plus 6.0 software (Media Cybernetics). Red indicated normal brain tissue, whereas pale gray indicated infarcted tissue. The infarct volume (\%) for each coronary section was calculated using the following formula: (the volume of the contralateral hemisphere - the volume of the nonlesioned ipsilateral hemisphere)/(the volume of the contralateral hemisphere $\times 2$ ). The total infarct volume (\%) was calculated by adding up the infarct volume (\%) of all seven sections and then divided by 7 .

MRI. The mice and rats were anesthetized using chloral hydrate (Sigma, 15307-500G-R), and brain imaging was performed using a 7.0-T magnetic resonance scanner (BRUKER, BioSpec, 70/20USR). The respiration and temperature of the animals were monitored throughout the procedure. The images were acquired using a $2 \mathrm{D}, \mathrm{T} 2$-weighted fast spin echo sequence with the following parameters: slice thickness $=0.50 \mathrm{~mm}$; FOV $=2 \mathrm{~cm}$; echo time $/$ repetition time $=26.7 / 2000 \mathrm{~ms}$; resolution $=$ $0.078 \times 0.078 \mathrm{~mm}$; echo train length $=4$; number of averages $=4$; and matrix size $=256 \times 256$. The infarct volume, expressed as a percentage of the contralateral hemisphere, was summed (a total of five slices), multiplied by the slice thickness and corrected for edema.

Immunofluorescence, TUNEL, and Fluoro-Jade B staining. The animals were anesthetized and then transcardially perfused with $0.1 \mathrm{M}$ sodium phosphate buffer, pH 7.4, followed by 4\% PFA in phosphate buffer for 15 min (mice) or $30 \mathrm{~min}$ (rats). Immunocytochemistry was performed as previously described (Wang et al., 2013b; Xiang et al., 2014; Li et al., 2015). Briefly, the brains were fixed in the $4 \%$ PFA solution for $6-8 \mathrm{~h}$ at room temperature, followed by immersion in phosphate buffer containing $30 \%$ sucrose overnight at $4^{\circ} \mathrm{C}$. Then, the brains were embedded in OCT solution and were sliced into 5 - $\mu \mathrm{m}$-thick (mice) or $10 \mu \mathrm{m}$-thick

\section{Table 1. Primers used for real-time $P C R$}

\begin{tabular}{|c|c|}
\hline Genes & Sequence \\
\hline$B C l 2$ forward & 5'-TGGTGGACAACATCGCCCTGTG-3' \\
\hline$B c 12$ reverse & 5'-GGTCGCATGCTGGGGCCATATA-3' \\
\hline Survivin forward & 5'-TTGGCGGAGGTTGTGGTGACGCCAT-3' \\
\hline Survivin reverse & 5'-TCGGGTTGTCATCGGGTTCCCAGCCTT-3' \\
\hline GAP-43 forward & 5'-AGCGGAGACAGAAAGTGCTGCT-3' \\
\hline GAP-43 reverse & 5'-TCAGCTTGGCTGCTTTCTGCAGT-3' \\
\hline Reg2 forward & 5'-TGATCAGCATGGCTCAGAACA-3' \\
\hline Reg2 reverse & 5'-TACCTGGCCTTGGCTGTATG-3' \\
\hline Pim-1 forward & 5'-GCTGCTCAAGGACACAGTCT-3' \\
\hline Pim- 1 reverse & $5^{\prime}$-CTCAGGGACAGGCACCATTT-3' \\
\hline CIAP2 forward & 5'-TGGAGATAGAGTGGCCTGCT-3' \\
\hline CIAP2 reverse & $5^{\prime}$-CGAAGCAGACTGACCCAAGT-3' \\
\hline CFLIP forward & $5^{\prime}$-GGAGGTAGATGGGCCATCAA-3' \\
\hline CFLIP reverse & 5'-TCCACGCATACACTTTGTCCA-3' \\
\hline
\end{tabular}

sections (rats) according to standard procedures. For the cultured primary neurons, the coverslips were fixed in ice-cold acetone, and the cryosections or coverslips were washed in PBS containing 10\% goat serum and were incubated overnight in the following primary antibodies at $4^{\circ} \mathrm{C}$ : mouse anti-NeuN (MAB377; 1:200; Millipore), chicken anti-MAP2 (ab5392; 1:100; Abcam), rabbit anti-OSMR $\beta$ (bs-5096R-Cy5; 1:50; Bioss), and rabbit anti-p-STAT3 (\#9145; 1:1000; Cell Signaling Technology). After washing with PBS, the sections were incubated with the following secondary antibodies for $1 \mathrm{~h}$ : goat anti-chicken $\operatorname{IgY}(\mathrm{H} \& \mathrm{~L}$, DyLight 488, ab96947; Abcam), AlexaFluor-488-conjugated donkey anti-mouse IgG (A21202; Invitrogen), and AlexaFluor-568-conjugated anti-rabbit IgG (A10042; Invitrogen). DAPI (S36939, Invitrogen) was used for nuclear staining, and Fluoro-Jade B (AG310, Millipore) staining was performed according to the manufacturer's protocol. For the TUNEL assay, the sections were assessed using an ApopTag Plus In Situ Apoptosis Fluorescein Detection Kit (S7111; Millipore) according to the manufacturer's protocol. The images were photographed under an OLYMPUS DX51 fluorescence microscope (Olympus) using DP2-BSW version 2.2 software (Olympus), and image analysis was performed using Image-Pro Plus 6.0 software.

Tissue preparation. After anesthetization, the animals were transcardially perfused with cold sodium phosphate buffer, and the brains were immediately removed. The olfactory bulbs and $1 \mathrm{~mm}$ sections of the anterior and posterior brain tissue were excised. The remaining tissues of the ipsilateral and contralateral hemispheres were harvested, immediately frozen in liquid nitrogen, and stored at $-80^{\circ} \mathrm{C}$.

$q R T-P C R$. Total RNA was extracted from the peri-infarct cortex defined as the cortical area within $2.5 \mathrm{~mm}$ radius from the necrotic core, using TRIzol reagent (Invitrogen) according to the manufacturer's protocol and was reverse-transcribed into cDNA using a Transcriptor First Strand cDNA Synthesis Kit (Roche). The LightCycler 480 SYBR Green 1 Master Mix (Roche) and the LightCycler 480 QPCR System (Roche) were used to perform qRT-PCR analysis. The PCR conditions were as follows: $95^{\circ} \mathrm{C}$ for $10 \mathrm{~min} ; 40$ cycles of $95^{\circ} \mathrm{C}$ for $10 \mathrm{~s}, 60^{\circ} \mathrm{C}$ for $10 \mathrm{~s}$, and $72^{\circ} \mathrm{C}$ for $20 \mathrm{~s}$; and a final extension at $72^{\circ} \mathrm{C}$ for $10 \mathrm{~min}$. The relative quantity of the mRNAs was calculated via normalization to the quantity of GAPDH mRNA. The primer pairs are shown in Table 1 .

Western blot analysis. The brain samples (collected from the same regions used for RNA extraction) or cultured cells were lysed in lysis buffer, and $50 \mu \mathrm{g}$ of extracted protein was separated on $8 \%-12 \%$ SDSPAGE gels and transferred to PVDF membranes (Millipore). The membranes were blocked in TBST containing 5\% skim milk powder for $1 \mathrm{~h}$ at room temperature and were then incubated in primary antibodies at $4{ }^{\circ} \mathrm{C}$ overnight. Next, the membranes were washed and then incubated with secondary antibodies for $1 \mathrm{~h}$ at room temperature. The signals were detected using a Bio-Rad ChemiDoc XRS + imager (Bio-Rad) and were quantified using Image Lab 5.1 (Bio-Rad). The following primary antibodies were used: rabbit anti-OSMR $\beta$ (sc30010; 1:200; Santa Cruz Biotechnology), rabbit anti-Bcl-2 (\#2870; 1:1000; Cell Signaling Technology), rabbit anti-Bax (\#2772; 1:1000; Cell Signaling Technology), rab- 


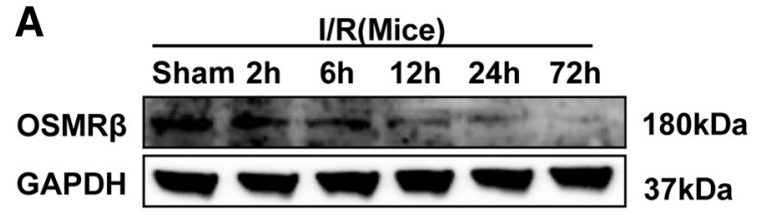

B

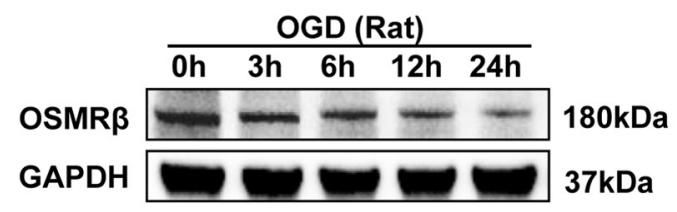

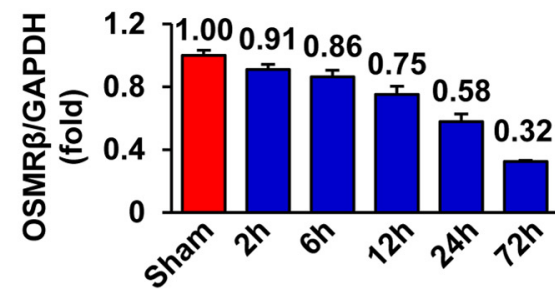

(I/R)

C
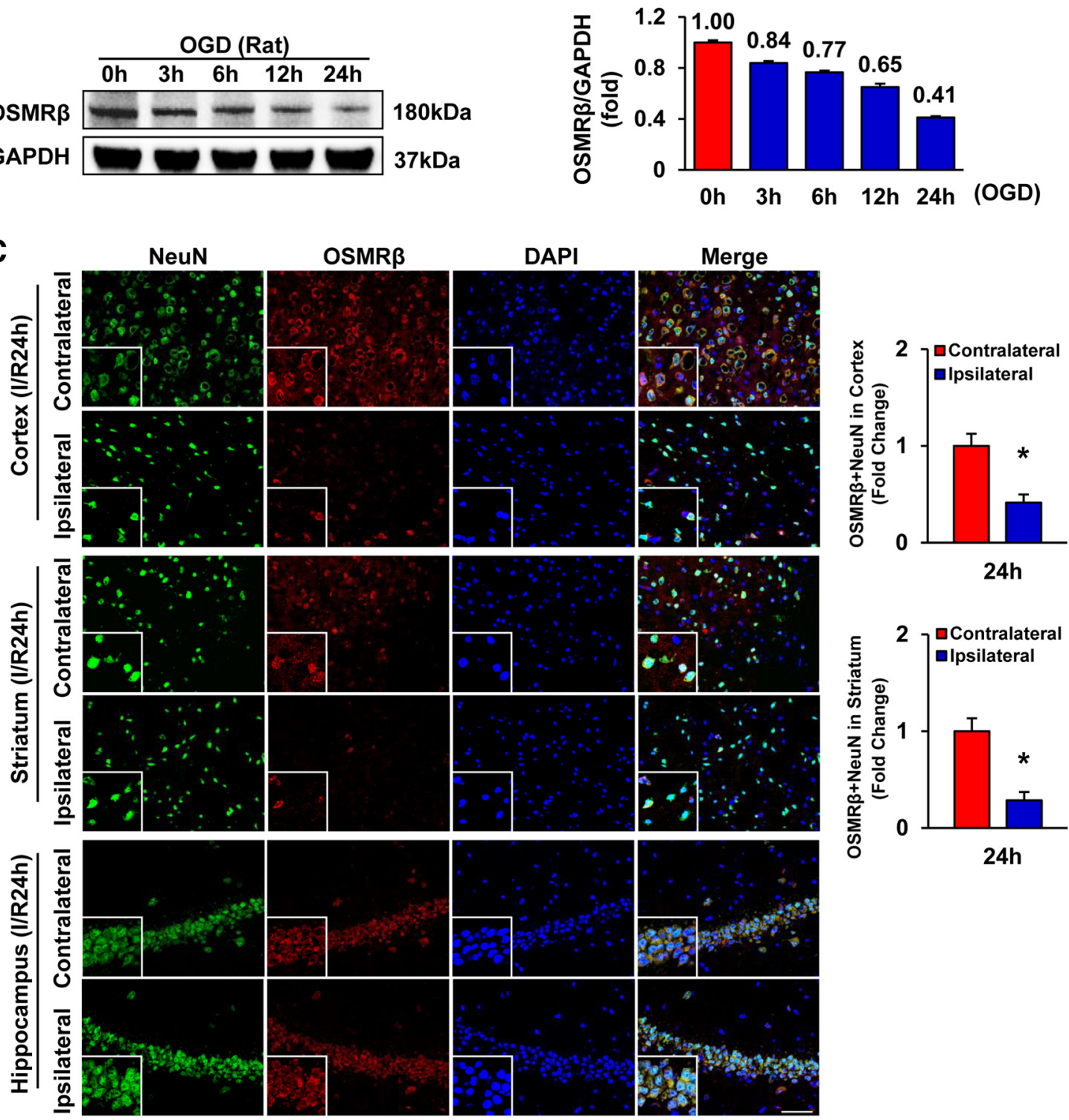

Figure 1. Ischemic injury reduces the expression of OSMRß. A, Mouse brain homogenates were extracted at the indicated times of MCAO/reperfusion. The Western blot analysis (left) and quantification (right) of OSMR $\beta$ expression are shown. $n=6$ per time point. $\boldsymbol{B}$, Homogenates of primary cortical neurons subjected to $0 \mathrm{GD} /$ reperfusion were collected for Western blot analysis at the indicated time points; $n=6$ per time point. $A, B, G$ APDH was used as a loading control. C, OSMR $\beta$ directly affects neurons during I/R. Mouse brains were stained for 0 SMR $\beta$ (red), NeuN (green), and DAPI (blue, nuclei) in the ipsilateral ( $24 \mathrm{~h}$ after I/R) and contralateral (control) hemispheres. Enlarged area insets, Images at higher magnification. $n=4 .{ }^{*} p<0.05$ versus contralateral. Error bars indicate mean \pm SE. Scale bars, $50 \mu \mathrm{m}$.

bit anti-cleaved caspase-3 (\#9661; 1:1000; Cell Signaling Technology), rabbit anti-caspase-3 (\#9662, 1:1000; Cell Signaling Technology), rabbit anti-cleaved caspase-9 (ab52298; 1:1000; Abcam), rabbit anti-caspase-9 (\#9504, 1:1000; Cell Signaling Technology), rabbit anti-p-MEK1/2 (\#9154; 1:1000; Cell Signaling Technology), rabbit anti-MEK1/2 (\#9122; 1:1000; Cell Signaling Technology), rabbit anti-p-ERK1/2 (\#4370; 1:1000; Cell Signaling Technology), rabbit anti-ERK1/2 (\#4695; 1:1000; Cell Signaling Technology), rabbit anti-p-JNK (\#4668; 1:1000; Cell Signaling Technology), rabbit anti-JNK (\#9258; 1:1000; Cell Signaling
Technology), rabbit anti-p-P38 (\#4511; 1:1000; Cell Signaling Technology), rabbit anti-P38 (\#9212; 1:1000; Cell Signaling Technology), rabbit anti-p-JAK2 (\#3776; 1:1000; Cell Signaling Technology), rabbit antiJAK2 (\#3230; 1:1000; Cell Signaling Technology), rabbit anti-p-STAT3 (\#9145; 1:1000; Cell Signaling Technology), rabbit anti-STAT3 (BS1336; 1:1000; Bioworld Technology), rabbit anti-survivin (\#2808; 1:1000; Cell Signaling Technology), rabbit anti-GAP-43 (ab12274; 1:1000; Abcam), goat anti-Reg2 (AF2035; 1:2000; R\&D Systems), rabbit anti-cIAP2 (sc7944; 1:200; Santa Cruz Biotechnology), rabbit anti-cFLIP (sc8347; 
A

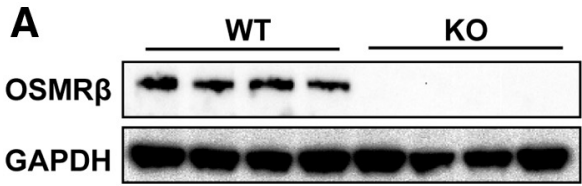

B

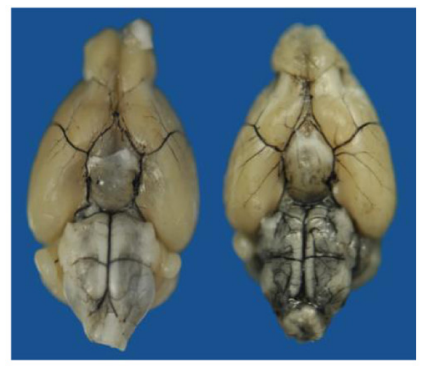

C

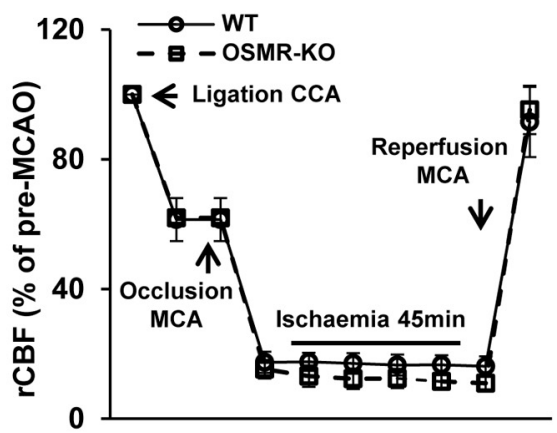

D $180 \mathrm{kDa}$
$37 \mathrm{kDa}$

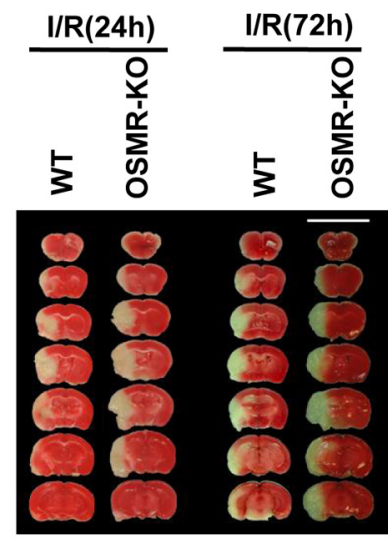

G

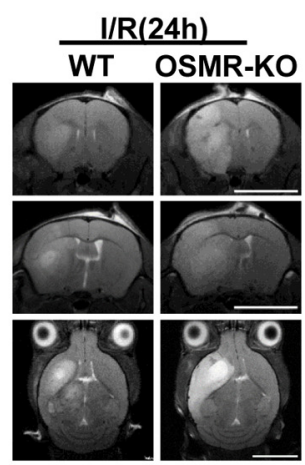

E

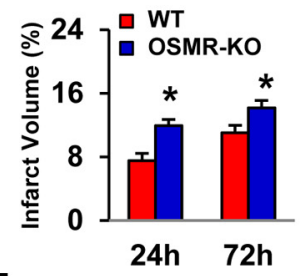

F
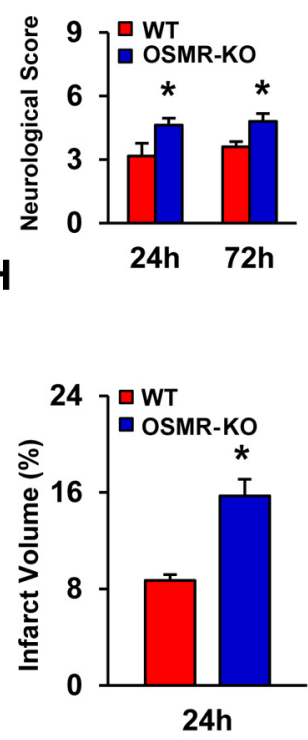

Figure 2. Deletion of OSMR $\beta$ exacerbates ischemic lesions. $A$, A representative Western blot of OSMR $\beta$ expression in OSMR-KO mice. GAPDH was used as a loading control. $B$, Representative images showing the integrity of the cerebral vasculature via India ink staining in OSMR-KO and WT mice. $n=5$. C, rCBF analysis in WT and OSMR-KO mice subjected to MCAO/reperfusion at the indicated time points and the quantified results $(n=6, p>0.05$ between strains). $\boldsymbol{D}, \boldsymbol{E}, \mathrm{TTC}$ (taining was performed on OSMR-KO and WT mice 24 or $72 \mathrm{~h}$ after $\mathrm{I} / \mathrm{R}(\boldsymbol{D})$, and the results were quantified using Image-Pro Plus 6.0 software (E). $\boldsymbol{F}$, Neurological function post-I/R was analyzed using neurological deficit scores. $n=7$. $\boldsymbol{G}$, Representative MRI scans of mouse brains $24 \mathrm{~h}$ after $\mathrm{I} / \mathrm{R}$. $\boldsymbol{H}$, Quantification of the infarct volumes. $n=3$ or $4 . E, F, H,{ }^{*} p<0.05$ versus the WT mice. Error bars indicate mean \pm SE.

Table 2. Physiological variables of WT, OSMR-KO, NTG, and OSMR-TG mice before $\mathrm{MCAO}^{a}$

\begin{tabular}{lllll}
\hline & WT & OSMR-KO & NTG & OSMR-TG \\
\hline DBP (mmHg) & $104.81 \pm 2.16$ & $103.04 \pm 3.72$ & $106.26 \pm 2.61$ & $104.37 \pm 1.50$ \\
SBP (mmHg) & $135.09 \pm 2.75$ & $133.13 \pm 1.06$ & $135.50 \pm 1.42$ & $132.07 \pm 0.54$ \\
Heart rate (bpm) & $626.70 \pm 6.87$ & $637.44 \pm 8.43$ & $636.00 \pm 7.45$ & $632.29 \pm 7.33$
\end{tabular}

${ }^{a}$ Blood pressure and heart rate were detected before MCAO. No significant differences were observed between groups. $n=4$ or 5 .

1:200; Santa Cruz Biotechnology), and the internal control rabbit antiGAPDH (\#2118; 1:1000; Cell Signaling Technology). The secondary antibodies were as follows: Peroxidase-AffiniPure Donkey Anti-Goat IgG ( $\mathrm{H}+\mathrm{L}$; Jackson ImmunoResearch Laboratories, 705-035-003), Peroxidase-AffiniPure Goat Anti-Mouse IgG ( $\mathrm{H}+\mathrm{L}$; Jackson ImmunoResearch Laboratories, 115-035-003), and Peroxidase-AffiniPure Goat Anti-Rabbit IgG (H+L; Jackson ImmunoResearch Laboratories, 111-035-003).

Cell culture and in vitro model of ischemia/reperfusion. Primary cortical neurons were obtained from SD rats within $1 \mathrm{~d}$ of birth as described previously (Lu et al., 2013; Wang et al., 2013a). Briefly, the neurons were dissociated in $2 \mathrm{ml}$ of $0.125 \%$ trypsin (Invitrogen) for $15 \mathrm{~min}$ at $37^{\circ} \mathrm{C}$, and the trypsin was then inactivated by adding $4 \mathrm{ml}$ of DMEM/F-12 (Invitrogen) containing 20\% FBS (Invitrogen). The collected cell suspension was centrifuged for $5 \mathrm{~min}$ at $184 \times g$ and then resuspended in DMEM containing 20\% FBS. After passing the suspension through $200 \mu \mathrm{m}$ sterile filters, the cells were seeded on plates coated with poly-L-lysine (10 $\mathrm{mg} / \mathrm{ml}$, Sigma). The neurons were cultured in Neurobasal medium (Invitrogen) supplemented with $\mathrm{B} 27$ (Invitrogen) for $24 \mathrm{~h}$ at $37^{\circ} \mathrm{C}$ in $5 \%$
$\mathrm{CO}_{2}$. Then, AraC (10 $\mu \mathrm{M}$, Sigma) was added to the medium $24 \mathrm{~h}$ after plating to inhibit cell proliferation; the medium was replaced every $48 \mathrm{~h}$. After culturing for $5 \mathrm{~d}$, the cells were used for experimentation. The neuronal cultures were exposed to transient OGD for $60 \mathrm{~min}$ and then returned to normal culture conditions for various periods. During OGD, the Neurobasal medium was replaced with serum-free, glucose-free Locke's buffer (154 mM $\mathrm{NaCl}, 5.6 \mathrm{~mm} \mathrm{KCl}, 2.3 \mathrm{~mm} \mathrm{CaCl}, 1 \mathrm{~mm} \mathrm{MgCl}, 3.6 \mathrm{~mm} \mathrm{NaHCO}_{3}, 5 \mathrm{~mm}$ HEPES, and $5 \mathrm{mg} / \mathrm{ml}$ gentamicin, $\mathrm{pH} 7.2$ ), and the cells were incubated in an experimental hypoxia chamber in a saturated atmosphere consisting of $95 \%$ $\mathrm{N}_{2}$ and $5 \% \mathrm{CO}_{2}$. The control cells were cultured in the presence of normal levels of glucose and were incubated for the same periods in a humidified atmosphere consisting of $95 \%$ air and $5 \% \mathrm{CO}_{2}$.

Recombinant adenoviral vectors and infection of neurons. Adenoviruses carrying sequences encoding mouse OSMR $\beta$ (AdOSMR), a short hairpin RNA targeting OSMR $\beta$ (AdshOSMR), constitutively active STAT3 (Adca-STAT3), or dominant negative STAT3 (Addn-STAT3) were constructed for in vitro studies as described previously (Zhang et al., 2008). Similar adenoviral vectors encoding the GFP gene (AdGFP) or scrambled short hairpin RNA (AdshRNA) were used as controls. The adenoviruses were transfected into cultured neurons at a multiplicity of infection of 100 for $48 \mathrm{~h}$.

Cell viability and $\mathrm{LDH}$ release. A nonradioactive cell counting kit-8 (CCK-8) assay (CK04, Dojindo) was used to examine cell viability. As an indicator of cell lysis, $\mathrm{LDH}$ release was determined via a colorimetric LDH cytotoxicity assay (G1782, Promega). The procedures of the assays were performed according to the manufacturer's instructions, and three independent experiments were performed.

Statistical analysis. All data were expressed as mean \pm SE. Differences between groups were determined via ANOVA followed by a post hoc 
A

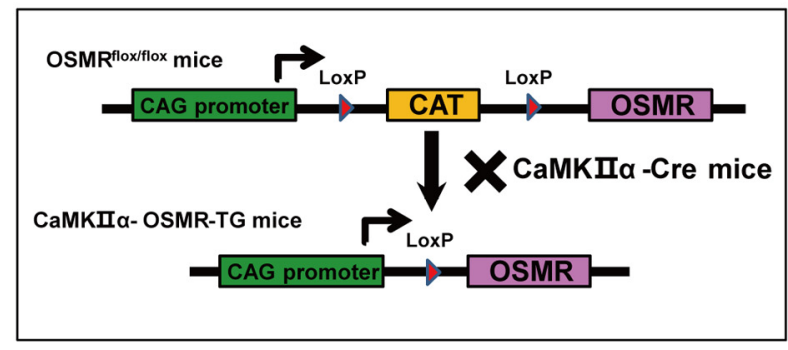

C

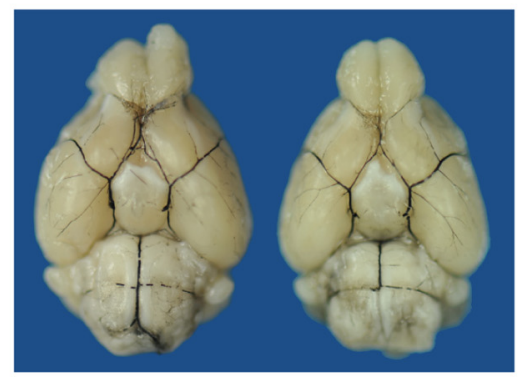

E

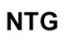

OSMR-TG4

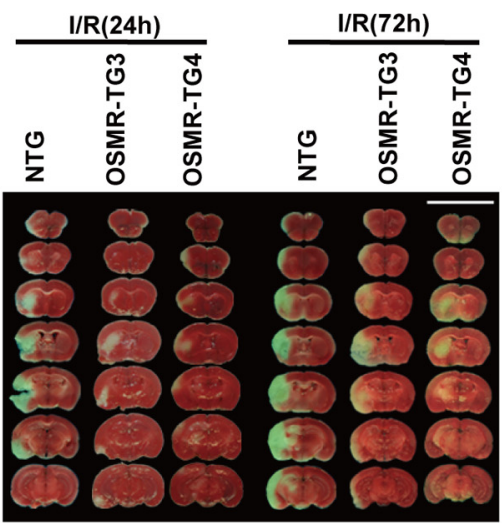

H

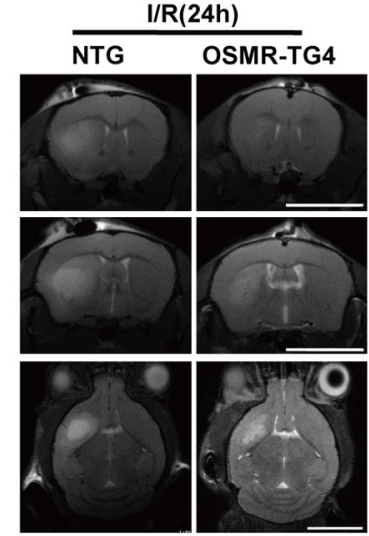

B
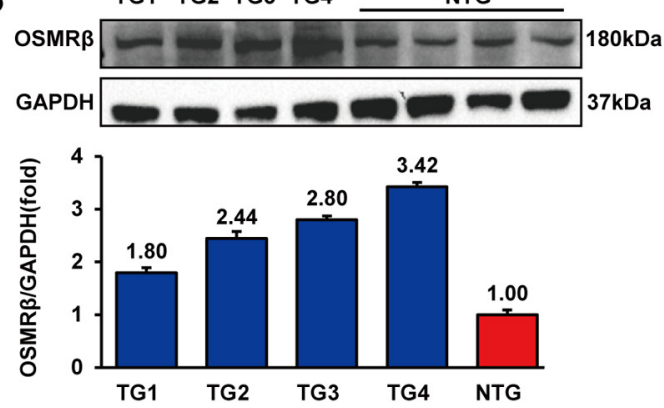

D

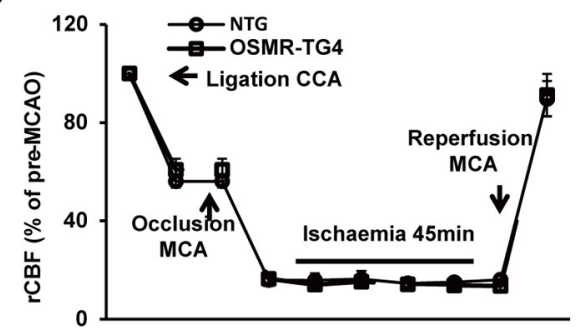

F

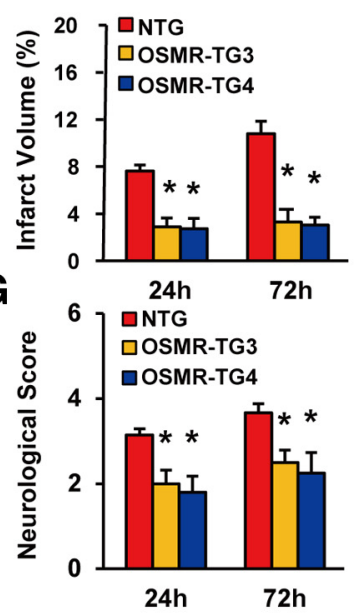

I

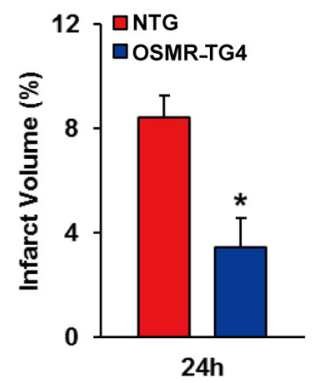

Figure 3. OSMR $\beta$ overexpression in neurons ameliorates ischemic lesions. A, Schematic workflow of the establishment of the neuron-specific OSMR $\beta$-overexpressing transgenic mouse strain. $B$, A representative Western blot of cerebral OSMR $\beta$ expression in OSMR-TG mice. GAPDH was used as a loading control. C, Representative images showing the integrity of the cerebral vasculature via India ink staining in OSMR-TG4 and NTG mice. $n=5$. D, rCBF analysis in NTG and OSMR-TG4 mice subjected to 45 min MCA0/reperfusion $(n=6, p>0.05$ between strains). $E, 0 S M R-T G$ mice exhibited reduced brain injury after stroke. TTC staining was performed on OSMR-TG and NTG mice 24 or $72 \mathrm{~h}$ after I/R (E), and the results were quantified using Image-Pro Plus 6.0 software $(\boldsymbol{F})$. $\boldsymbol{G}$, Neurological function after I/R was analyzed using neurological deficit scores. $n=7$. $\boldsymbol{H}$, Representative MRI scan of a mouse brain $24 \mathrm{~h}$ after $\mathrm{I} / \mathrm{R}$. $\boldsymbol{I}$, Quantification of the infarct volumes. $n=3$ or 4 . $F, G, I, * 00.05$ versus the NTG mice. Error bars indicate mean $\pm S E$. 
A

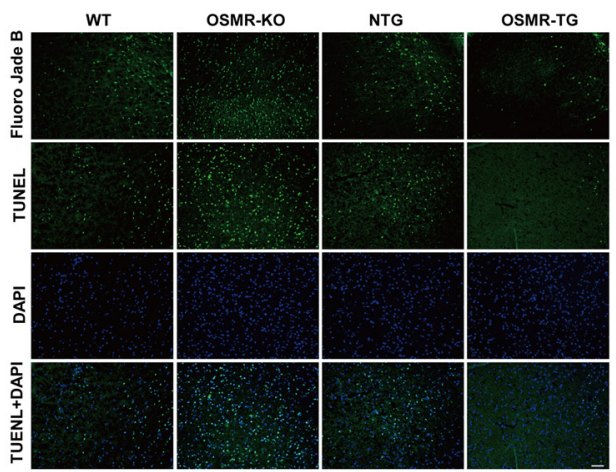

B
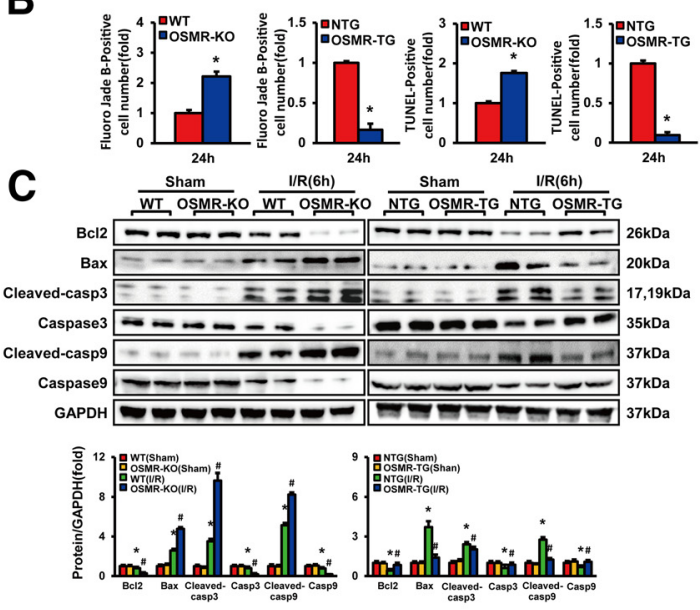

D

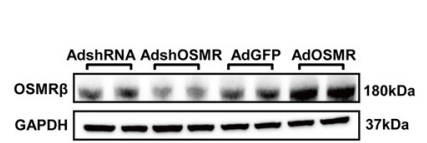

E $\mathbf{F}$
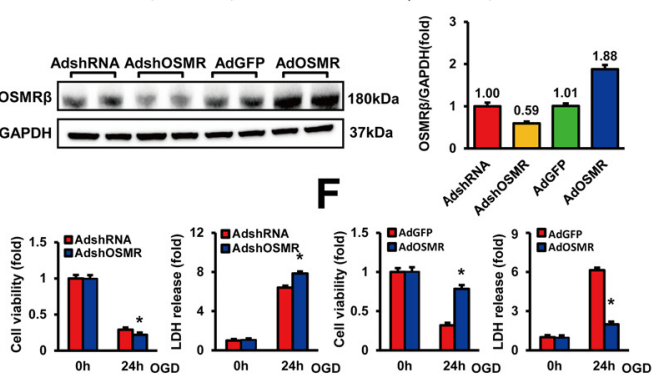

G

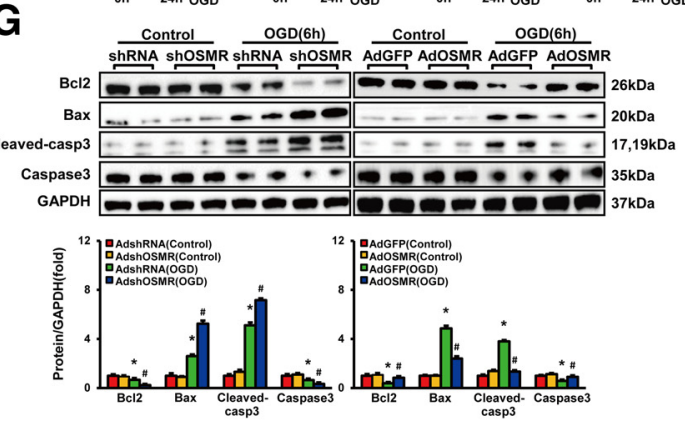

Figure 4. OSMR $\beta$ positively regulates neuronal survival after stroke. $\boldsymbol{A}, \boldsymbol{B}$, The cortices from the indicated mouse strains were analyzed via Fluoro-Jade $B$ and TUNEL staining at $24 \mathrm{~h}$ after $\mathrm{I} / \mathrm{R}$ $(\boldsymbol{A})$, and the numbers of Fluoro-Jade B- and TUNEL-positive neurons were quantified $(\boldsymbol{B}) . n=3$ or $4 .{ }^{*} p<0.05$ versus the WT (left) or NTG (right) mice. C, Brain homogenates from sham- and MCAO-operated OSMR-KO (left) and OSMR-TG (right) mice were analyzed via Western blotting using antibodies against the indicated proteins. The results were normalized to GAPDH expression, and the respective cerebral protein levels are shown graphically. $n=6$. $^{*} p<0.05$ versus sham. ${ }^{\#} p<0.05$ versus the WT (left) or NTG mice (right). Error bars indicate mean \pm SE. $D$, OSMR $\beta$ is neuroprotective in vitro. Primary neurons were infected with AdshOSMR, AdOSMR, or a control adenovirus. $n=6$ per group. The overexpression (AdOSMR) or silencing (AdshOSMR) of OSMR $\beta$ was validated via Western blotting using an anti-OSMR $\beta$ antibody. $\boldsymbol{E}, \boldsymbol{F}$, Cell viability $(\boldsymbol{E})$ and $\mathrm{LDH}$ release assays $(\boldsymbol{F})$ were performed on primary neurons infected with the indicated adenoviruses and subjected to OGD or the control treatment. $n=9$. ${ }^{*} p<0.05$ compared with
Tukey test. Comparisons between two groups were performed using an unpaired Student's $t$ test, and $p<0.05$ was considered significant. The in vivo and imaging studies were performed in a blinded manner.

\section{Results}

OSMR $\beta$ expression levels are decreased during cerebral ischemia/reperfusion

Previous studies had identified $O S M R \beta$ expression in several cell types in the brain, including neurons and astrocytes but not microglia. However, the OSMR $\beta$ expression profile following the onset of stroke remained unclear (Hsu et al., 2015). To address this issue, we analyzed the alterations in the OSMR $\beta$ expression levels during ischemic stroke using multiple in vivo and in vitro stroke models. We first used a mouse model of MCAO/reperfusion. In response to MCAO for $45 \mathrm{~min}$ followed by reperfusion for $2-72 \mathrm{~h}$ after stroke onset, OSMR $\beta$ expression decreased in brain homogenates in a time-dependent manner (Fig. $1 A$ ). Furthermore, a significant reduction in $O S M R \beta$ expression was observed as early as $2 \mathrm{~h}$ after MCAO and was further diminished to $\sim 32.5 \%$ of its normal expression level in the brain $72 \mathrm{~h}$ after MCAO (Fig. 1A). Considering the potential systemic interference, such as inflammatory response, we isolated rat primary cortical neurons and subjected them to OGD for $1 \mathrm{~h}$, followed by normal culture conditions for the indicated periods (Fig. 1B). As shown in Figure $1 B$, neurons subjected to OGD displayed a robust decrease in the expression of OSMR $\beta$ after $24 \mathrm{~h}$. Thus, neuronal OSMR $\beta$ may be a potential therapeutic target during ischemic stroke. To further test this hypothesis, we performed immunofluorescence staining for $\operatorname{OSMR} \beta$ and a neuronal marker in different regions of the brain. MCAO/reperfusioninduced cerebral lesions were observed on cortical and striatal neurons, but not on neurons in the hippocampus, where blood flow was preserved (Engel et al., 2011). Interestingly, OSMR $\beta$ expression was enriched in the contralateral (control) cortex, striatum, and hippocampus (Fig. 1C), and was decreased by $58.6 \%$ and $71.5 \%$ in the ipsilateral cortex and striatum, respectively, compared with the corresponding contralateral regions (Fig. 1C). Together, this reduction in neuronal OSMR $\beta$ expression indicates its biological importance in mice.

\section{Exacerbation of ischemia/reperfusion-induced cerebral injury upon neuronal OSMR $\beta$ ablation}

Given the decrease in neuronal OSMR $\beta$ expression following stroke, we next investigated the biological effects of OSMR $\beta$ ablation in neurons. OSMR-KO mice were purchased from RIKEN BioResource Center, and the absence of OSMR $\beta$ expression in these mice was confirmed via immunoblotting (Fig. $2 A$ ). The established OSMR-KO mouse strain showed no signs of compromised vascular integrity (Fig. $2 B$ ), and both the WT and OSMR-KO mice displayed comparable $\mathrm{rCBF}$ in response to I/R (Fig. 2C). OSMR $\beta$ ablation had no impact on blood pressure and heart rate (Table 2). Compared with the WT mice, the OSMR-KO mice exhibited an increase in the infarct volume by $~ 58.5 \%$ and $28.5 \%$ at 24 and $72 \mathrm{~h}$ after MCAO, respectively (Fig. 2D,E). Functionally, the OSMR-KO mice exhibited more severe neurological deficits at both time points $(46.1 \%$ increase at $24 \mathrm{~h}$ and

AdshRNA or AdGFP. G, Representative Western blots of the expression of the indicated proteins in cell lysates from AdshOSMR- or AdOSMR-infected primary neurons. The results were normalized to GAPDH expression, and the respective cerebral protein levels are shown graphically. $n=$ 6. ${ }^{*} p<0.05$ versus control. ${ }^{\#} p<0.05$ versus AdshRNA (left) or AdGFP (right). Error bars indicate mean $\pm \mathrm{SE}$. 


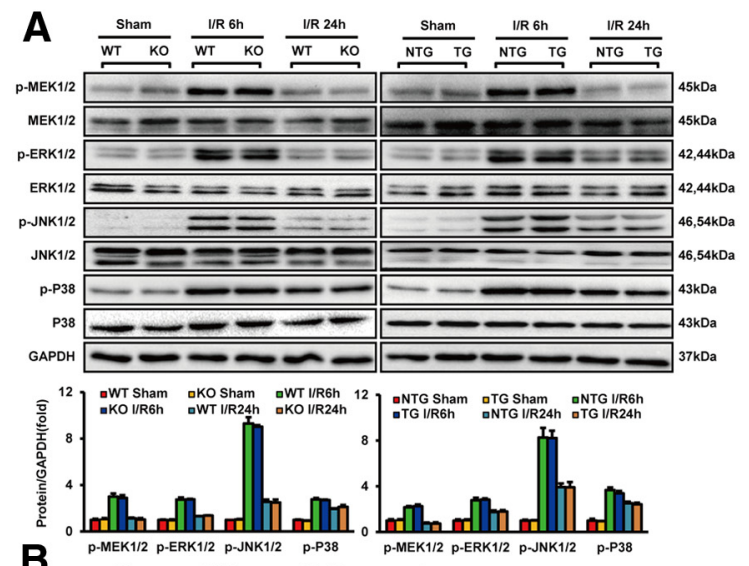

E
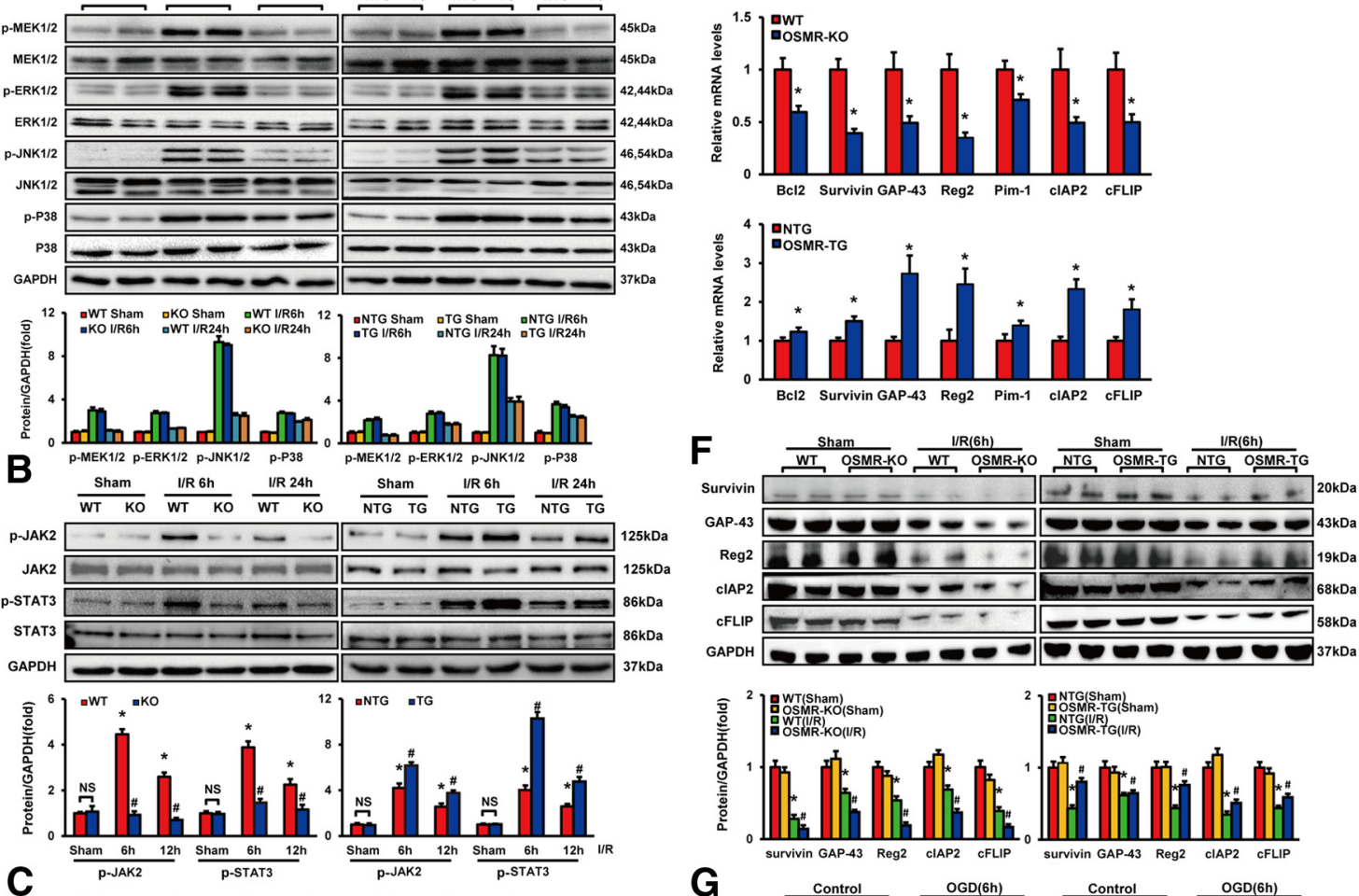

C Control $6 \mathrm{~h} \quad{ }_{12 \mathrm{~h}}{ }_{24 \mathrm{~h}}$ control ${ }_{6 \mathrm{~h}} \frac{12 \mathrm{~h}}{24 \mathrm{~h}}$ OGD

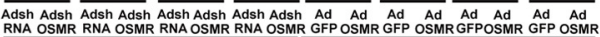
RNA OSMR RNA OSMR RNA OSMR RNA OSMR GFP OSMR GFP OSMR GFPOSMR GFP OSMR
JAK2 $125 \mathrm{kDa}$

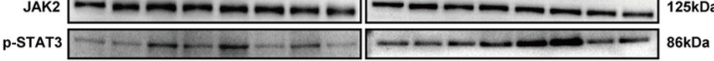

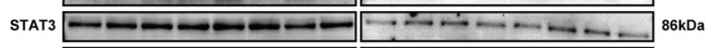

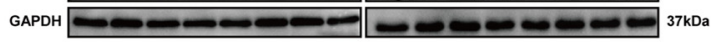
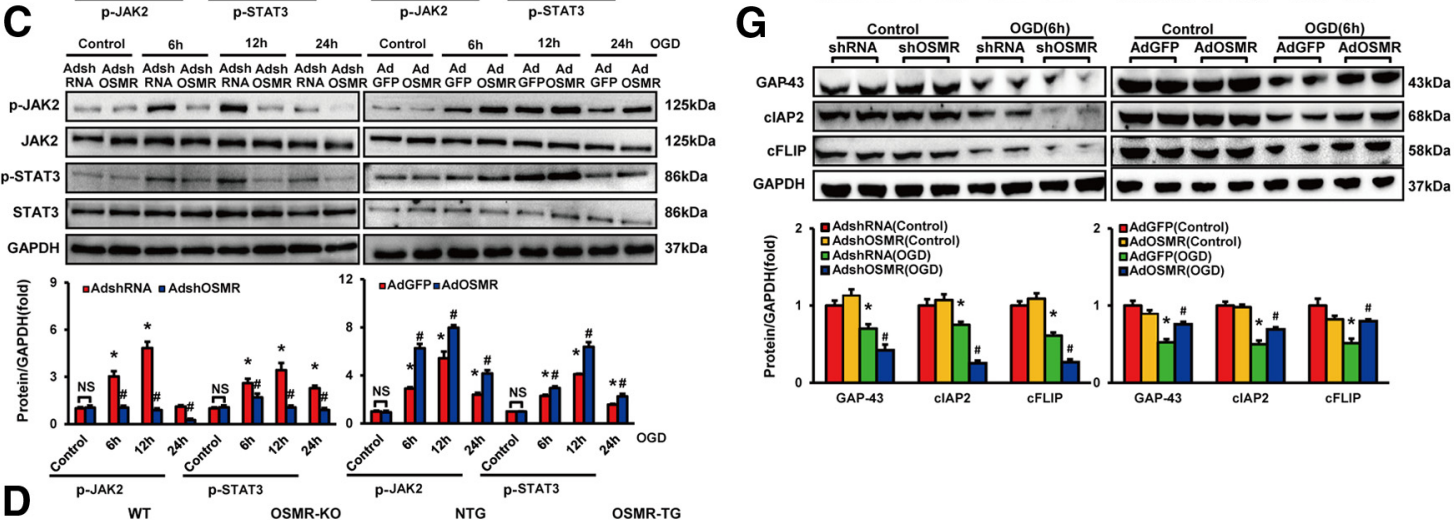

D
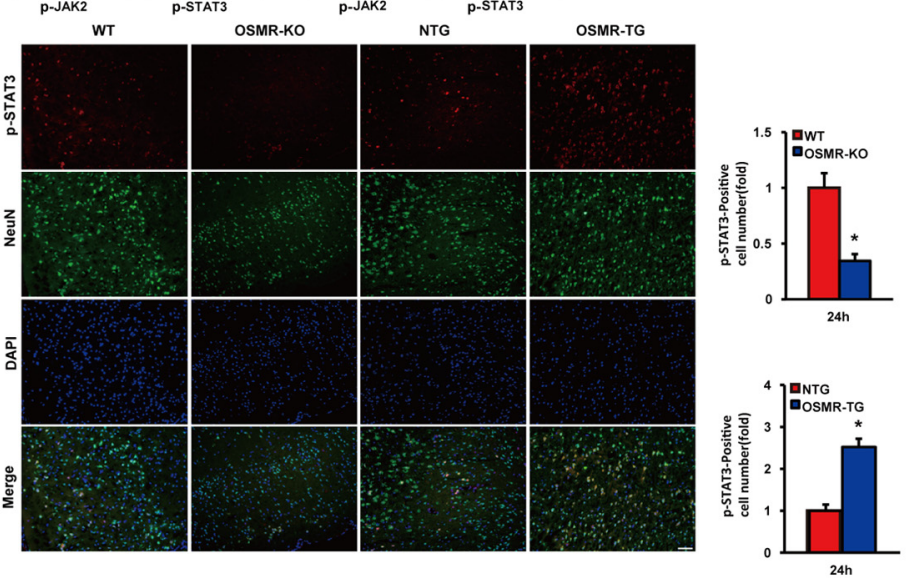

Figure 5. OSMR $\beta$ activates the JAK2/STAT3, but not MAPK, cascade after I/R. $A, B$, Brain homogenates from sham- or MCAO-operated OSMR-KO (left) and OSMR-TG (right) mice were extracted. Western blot analysis of MAPK $(\boldsymbol{A})$ and JAK2/STAT3 ( $\boldsymbol{B})$ signaling pathway members was performed. The results were normalized to GAPDH expression, and the expression ratios of phosphorylated JAK2 and STAT3 to the corresponding total proteins were calculated. $n=6 .{ }^{*} p<0.05$ compared with sham. ${ }^{\#} p<0.05$ compared with the WT (left) or NTG (right) control littermates (C). Western blot analysis of the JAK2/STAT3 cascade in cell lysates harvested from AdshOSMR- or AdOSMR-infected primary neurons. ${ }^{*} p<0.05$ compared with control. ${ }^{\#} p<0.05$ compared with the AdshRNA (left) or AdGFP (right) controls. NS, Not significant. D, OSMR $\beta$ positively regulates STAT3 phosphorylation in neurons. Representative images of NeuN-, p-STAT3-, and DAPI-stained primary neurons are shown. The quantification of p-STAT3-positive neurons is depicted graphically. $n=3$ or $4 .{ }^{*} p<0.05$ versus WT (left) or NTG (right) mice. $\boldsymbol{E}-\boldsymbol{G}$, The $m$ RNA $(\boldsymbol{E})$ and protein levels $(\boldsymbol{F}, \boldsymbol{G})$ of OSMR $\beta$-regulated genes were determined via RT-PCR and Western blot analysis, respectively, in MCAO-injured mice $(\boldsymbol{E}, \boldsymbol{F})$ or $0 \mathrm{GD}$-treated primary neurons $(\boldsymbol{G})$. The results were normalized to GAPDH expression, and the relative protein levels are shown. Error bars indicate mean $\pm \mathrm{SE}$. 
A

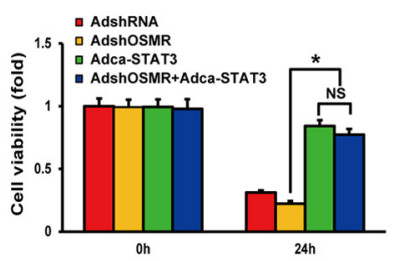

B
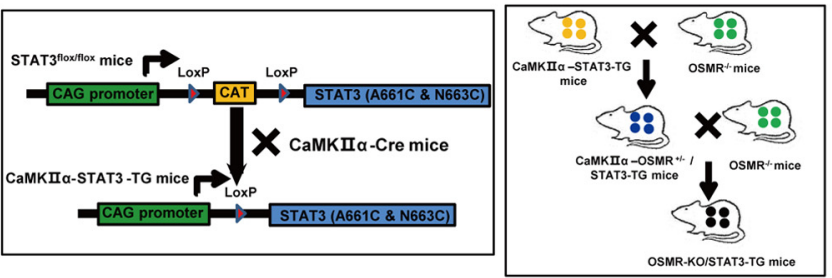

E
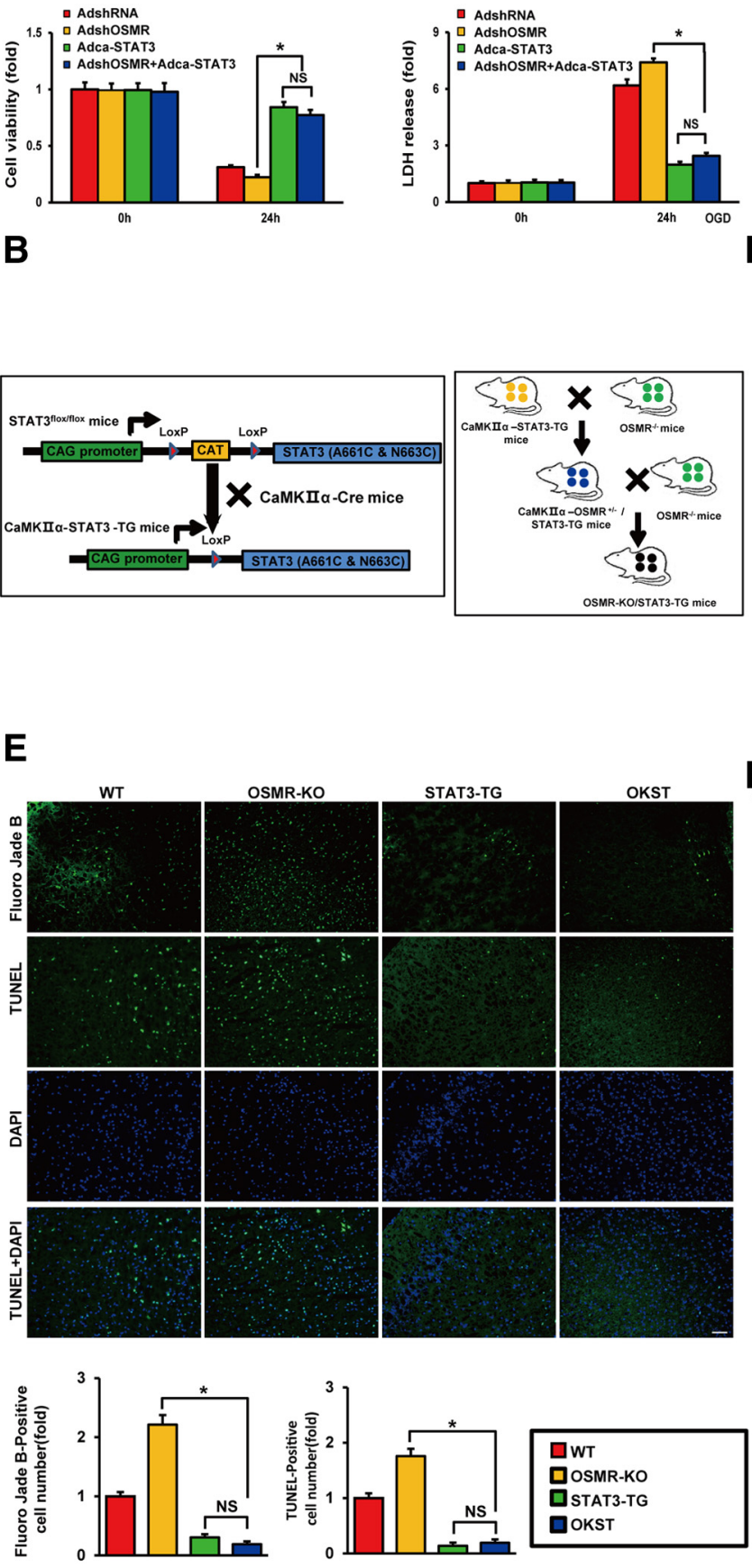

口OSMR-KO

口STAT3-TG

口OKST

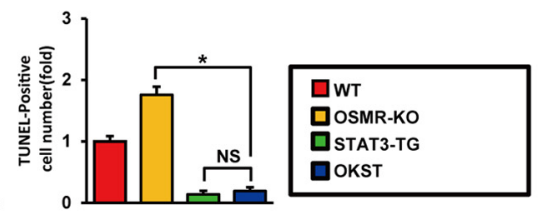

D
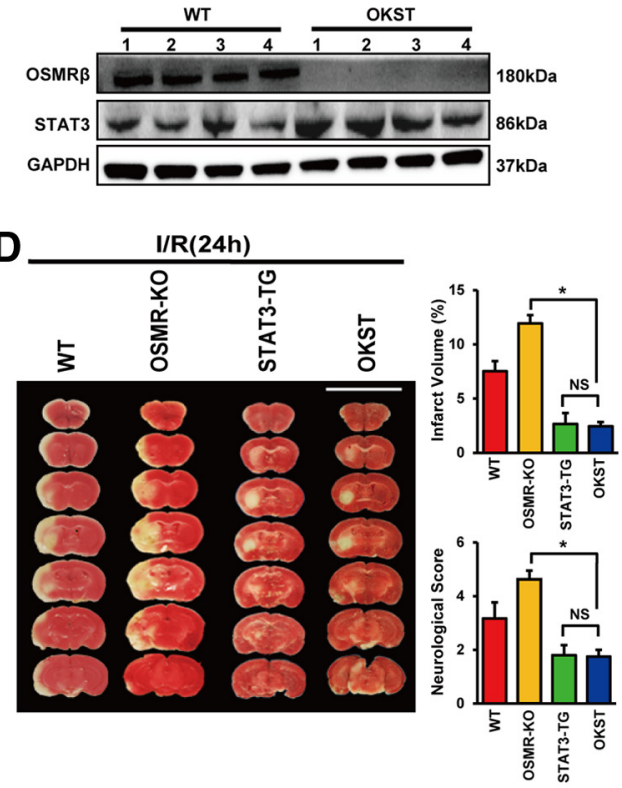

$\mathbf{F}$
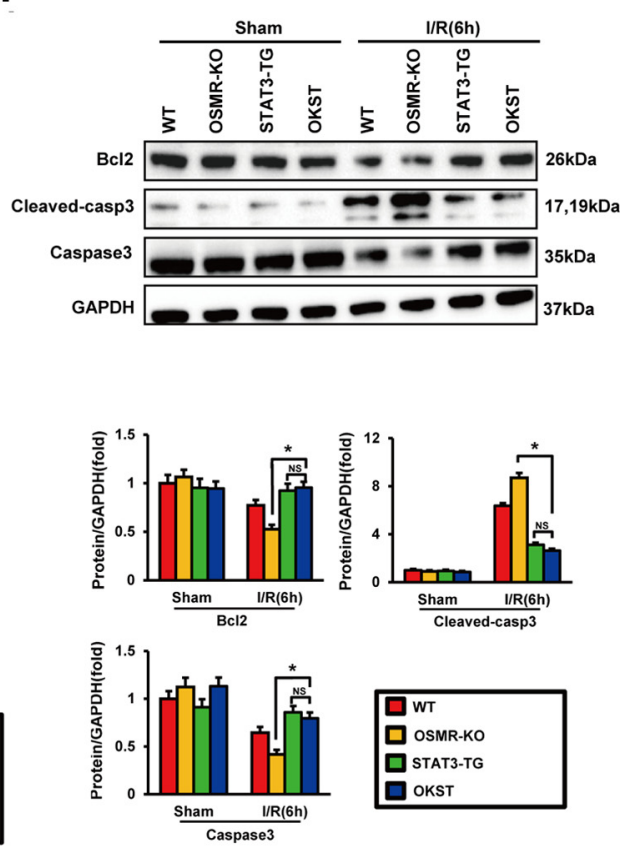

Figure 6. STAT3 overexpression mimics the protective effect of OSMR $\beta$. A, Cell viability and LDH release assays were performed on primary neurons infected with AdshOSMR or Adca-STAT3, or both, and subjected to OGD or the control treatment. ${ }^{*} p<0.05$ compared with AdshOSMR. NS, Not significant. B, Schematic of the generation of STAT3-TG (left) and OKST mice (right). C, The 0SMR $\beta$ and STAT3 protein levels in OKST mice were detected using Western blotting. $\boldsymbol{D}$, The detrimental effect of OSMR $\beta$ ablation on stroke outcomes was rescued by the joint overexpression of STAT3. TTC staining was performed on the indicated mouse strains (left). The infarct size and neurological deficit scores were quantified (right). $n=6-8 . E$, Fluoro-Jade B and TUNEL staining were performed on the indicated mouse strains at $24 \mathrm{~h}$ after I/R, and the numbers of Fluoro-Jade $B$ - and TUNEL-positive neurons were quantified. $n=3$ or 4 . $F$, Western blot analysis of BCI2, cleaved caspase-3, and total caspase-3 expression in sham- or MCAO-operated mice from the indicated genetic background. The results were normalized to GAPDH expression, and the relative cerebral protein levels are shown graphically. $n=6 . D-F,{ }^{*} p<0.05$ versus the OSMR-KO mice. NS, Not significant. Error bars indicate mean $\pm \mathrm{SE}$.

$33.3 \%$ increase at $72 \mathrm{~h}$ ) (Fig. 2F). In vivo, the lesion size of the OSMR-KO mice was enlarged by $\sim 1.8$-fold compared with the WT mice $24 \mathrm{~h}$ after MCAO, as demonstrated by observation (Fig. $2 G$ ) and quantification (Fig. $2 H$ ) of MRI scans. Together, we found that decreasing the expression of OSMR $\beta$ in neurons might exacerbate cerebral lesions after $\mathrm{I} / \mathrm{R}$.
Reduced ischemia/reperfusion-induced cerebral injury in OSMR $\boldsymbol{\beta}$-overexpressing mice

Next, we proposed that, if $O S M R \beta$ expression is essential for the survival of cerebral tissues in ischemic stroke, OSMR $\beta$ overexpression may be cerebroprotective. Thus, we specifically overexpressed OSMR $\beta$ in neurons by crossing OSMR flox/flox mice with 
A

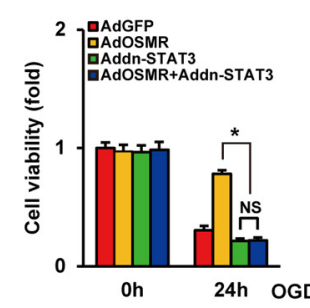

B

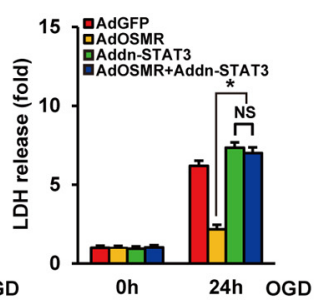

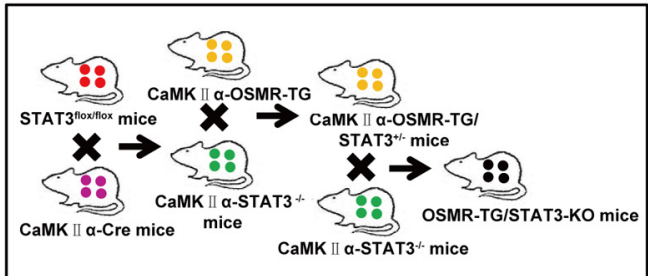

$\operatorname{liR(24h)}$

C

D

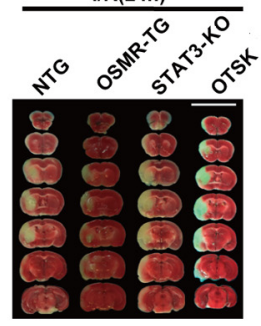

$\mathbf{F}$
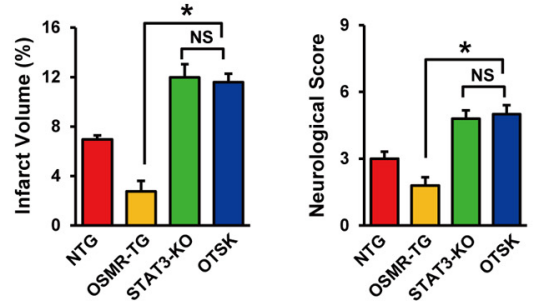

E
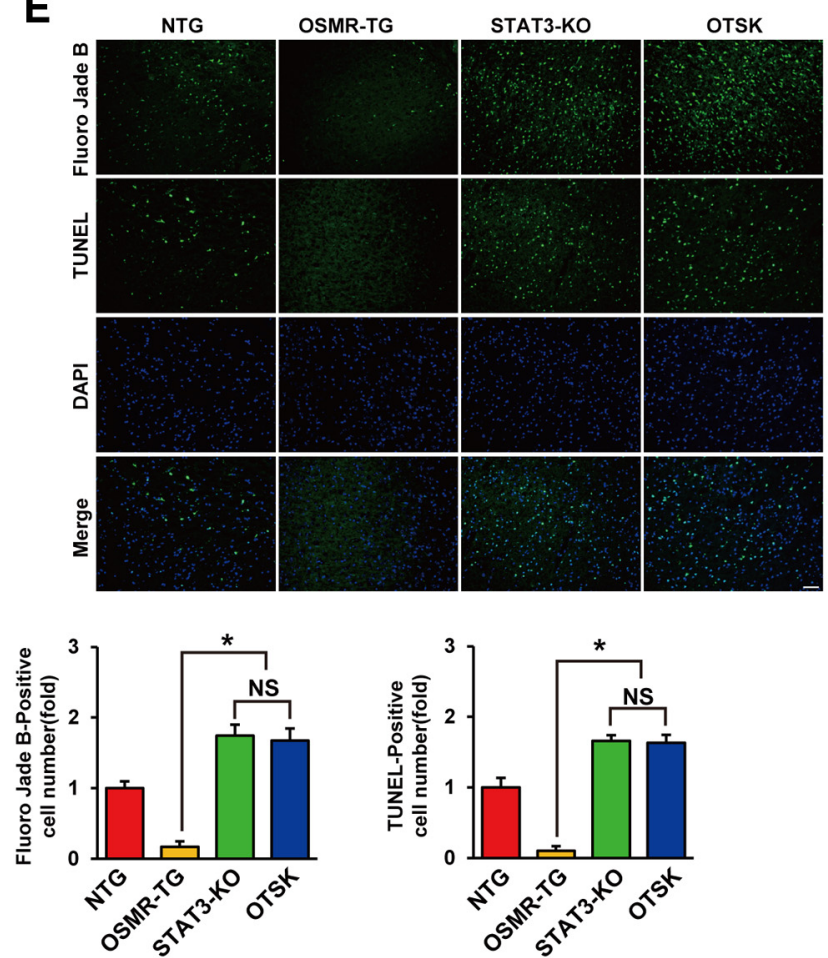

Figure 7. The neuroprotective effect of OSMR $\beta$ is STAT3-dependent. $A$, Cell viability and LDH release assays were performed on primary neurons infected with AdOSMR or Addn-STAT3, or both, and subjected to $0 G D$ or the control treatment. ${ }^{*} p<0.05$ compared with AdOSMR. NS, Not significant. $B$, Schematic of the generation of STAT3-KO and OTSK mice (right). C, The OSMR $\beta$ and STAT3 protein levels were detected in the OTSK mice using Western blotting. $D, O S M R \beta$ overexpression does not protect the brain against $\mathrm{I} / \mathrm{R}$ injury in the absence of STAT3. TTC staining was performed on the indicated mouse strains (left). The infarct size and neurological deficit scores were quantified (right). $n=6$. E, Fluoro-Jade B and TUNEL staining were performed on the indicated mouse strains $24 \mathrm{~h}$ after $\mathrm{I} / \mathrm{R}$, and the numbers of Fluoro-Jade $\mathrm{B}$ - and TUNEL-positive neurons were quantified. $n=3-5$. $\boldsymbol{F}$, Western blot analysis of $\mathrm{B} \mathrm{Cl}$, cleaved caspase-3, and total caspase-3 expression in shamor MCA0-operated mice from the indicated genetic background. The results were normalized to GAPDH expression, and the relative cerebral protein levels are shown graphically. $n=6 . \mathbf{D}-\boldsymbol{F},{ }^{*} p<$ 0.05 versus the OSMR-TG mice. NS, Not significant. Error bars indicate mean \pm SE.

mice carrying a Cre recombinase driven by the neuron-specific promoter CaMKII $\alpha$ (Fig. 3A). Among the four established mouse strains, the OMSR-TG4 mice displayed the highest expression of $\operatorname{OSMR} \beta$ (3.42-fold higher than that in the WT mice) in the brain, whereas the OSMR $\beta$ expression in the OSMR-TG3 mice was moderate (2.80-fold) (Fig. $3 B$ ). The functional role of $O S M R \beta$ overexpression in ischemic stroke was not associated with its impact on vascular integrity (Fig. 3C), rCBF (Fig. 3D), or physiological variables (Table 2). As expected, both the OSMR-TG3 and OSMR-TG4 mice histologically (Fig. $3 E, F)$ and functionally (Fig. $3 G$ ) exhibited significantly improved stroke outcomes at 24 and $72 \mathrm{~h}$ following I/R compared with the nontransgenic (NTG) mice. Intriguingly, both mouse strains exhibited comparable neuroprotection, and this effect was confirmed by MRI of live OSMR-TG4 (hereafter referred to as OSMR-TG) mice (Fig. $3 H, I$ ). Thus, these findings strongly suggest that $\mathrm{OSMR} \beta$ protects the brain by directly functioning in neurons. 
A

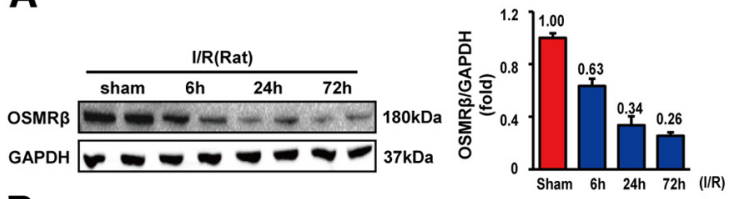

B
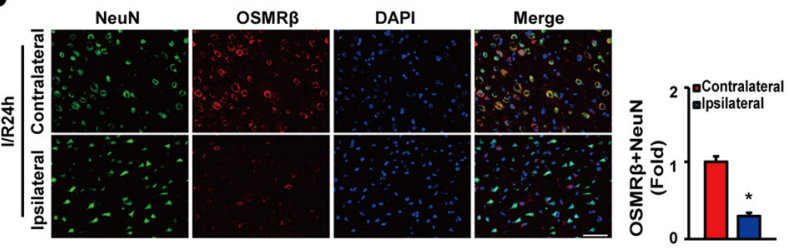

C

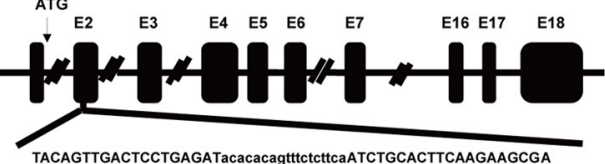

D

TACAGITGACTCCTGAGATTCagttrtcttcaATCTGCACTTCAAGAAGCGA

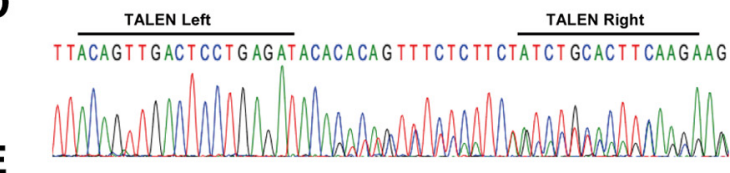

E

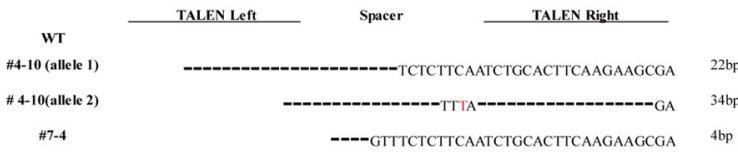

$\mathbf{F}$

G

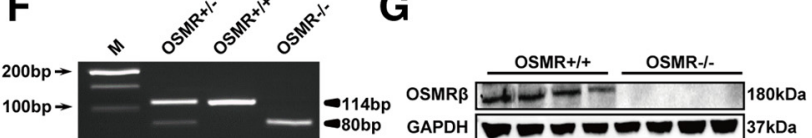

H
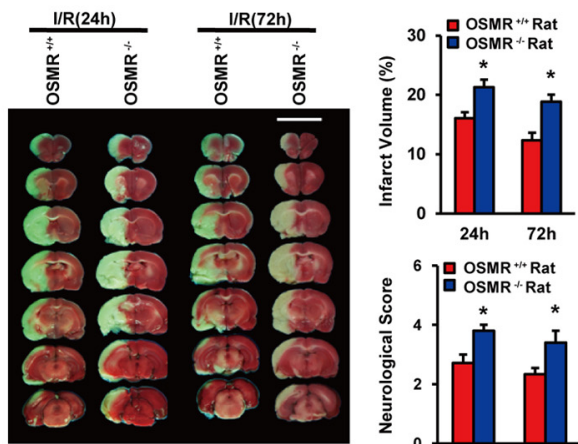

I
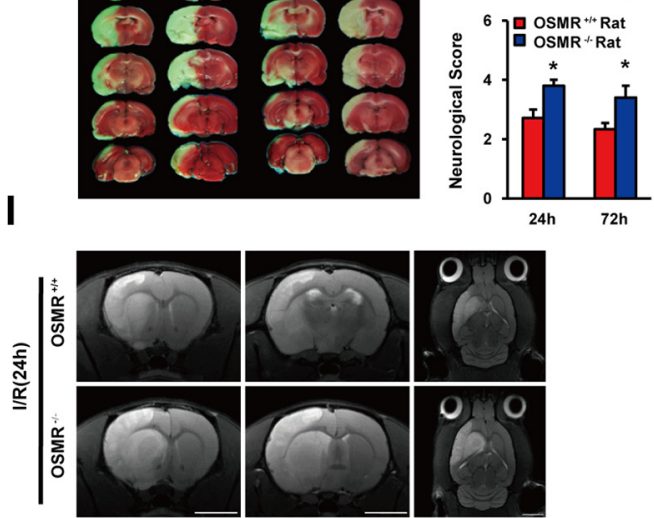
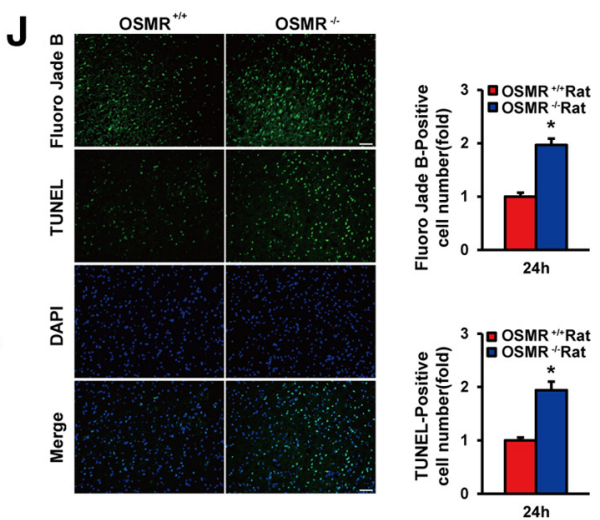

K

K

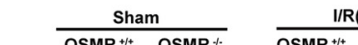

I/R(6h)
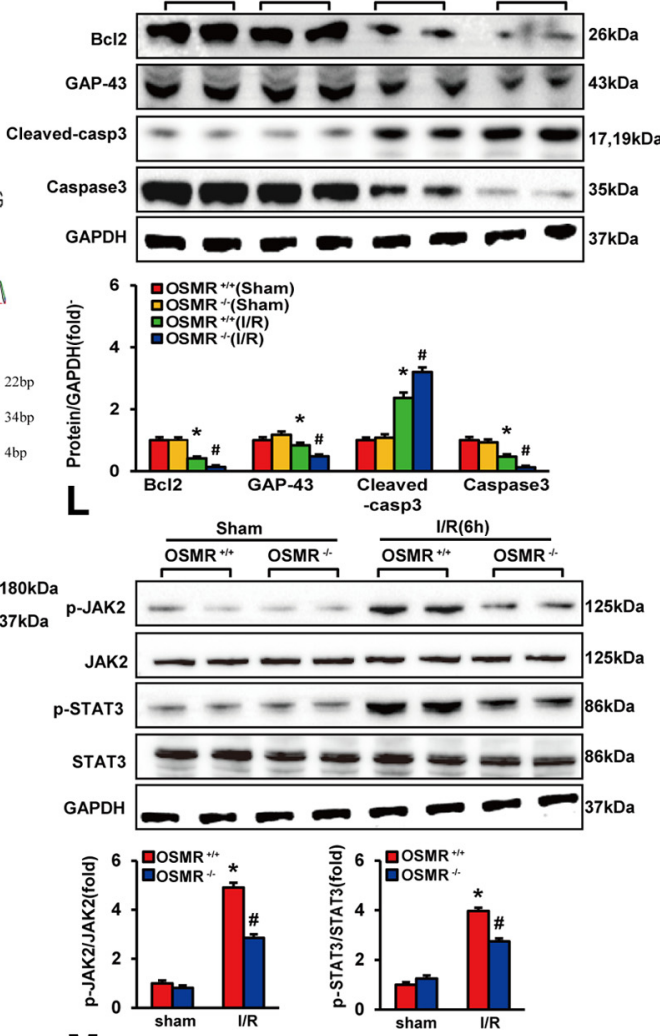

M
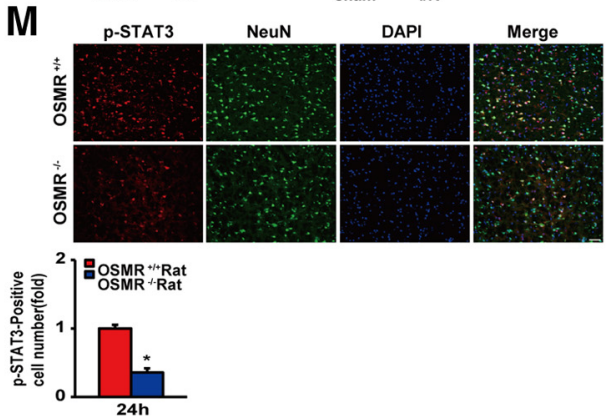

Figure 8. $\quad O S M R \beta$ ablation is detrimental to rats. $A$, Rat brain homogenates were extracted after the indicated time points after MCA0/reperfusion. Western blot analysis (left) and quantification (right) of OSMR $\beta$ expression were performed. GAPDH served as a loading control. $n=3$ per time point. $\boldsymbol{B}$, The ipsilateral ( $24 \mathrm{~h}$ after I/R) and contralateral (control) hemispheres of rat brains were stained for OSMR $\beta$ (red), NeuN (green) and DAPI (blue, nuclei). $n=3$ or $4 .{ }^{*} p<0.05$ versus contralateral. Scale bars, $50 \mu \mathrm{m}$. C, The design of an OSMR $\beta$-targeting TALEN. $\boldsymbol{D}, \boldsymbol{E}$, The mutant sequence for the homozygous $F 1$ lines used in this study. $\boldsymbol{F}$, Validation of OSMR $\beta$ knock-out using quantitative PCR. $G$, The OSMR $\beta$ protein levels were detected in OSMR ${ }^{-/-}$and $05 M R^{+/+}$rats using Western blotting. $\boldsymbol{H}, \mathrm{TTC}$ staining was performed on $0 S M R^{-1-}$ and $O S M R^{+/+}$rats. The infarct size and neurological deficit scores were quantified (right). $n=6$ or $7 . \boldsymbol{I}$, Representative MRI scan of rat brains $24 \mathrm{~h}$ after I/R. J, Fluoro-Jade $B$ and TUNEL staining were performed on the indicated mouse strains $24 \mathrm{~h}$ after $\mathrm{I} / \mathrm{R}$, and the numbers of Fluoro-Jade B- and TUNEL-positive neurons were quantified (right). $n=3-5 . \boldsymbol{K}, \boldsymbol{L}$, Western blot analysis of BCl2, GAP-43, cleaved caspase-3, and total caspase-3 expression (K), as well as the expression of JAK2/STAT3 signaling pathway members $(\boldsymbol{L})$, in sham- or MCAO-operated rats with or without OSMR $\beta$ ablation. The results were normalized to GAPDH expression, and the respective cerebral protein levels are shown graphically. $n=6 .{ }^{\#} p<0.05$ versus OSMR ${ }^{+1+} . M$, Representative images of $p$-STAT3 (red), NeuN (green), or DAPI (blue, nucleus) staining in the ipsilateral (24h $\mathrm{l} / \mathrm{R}$ ) and contralateral (control) hemispheres from $0 S M R^{+1+}$ and $0 S M R^{-1-}$ rats. $n=4 .{ }^{*} p<0.05$ versus $0 S M R^{+1+}$ rats. Scale bars, $50 \mu \mathrm{m}$. Error bars indicate mean \pm SE. 


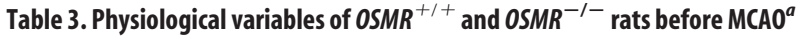

\begin{tabular}{lrr}
\hline & \multicolumn{1}{c}{ OSMR } & \multicolumn{1}{c}{ OSMR } \\
\hline DBP $(\mathrm{mmHg})$ & $97.64 \pm 2.17$ & $93.28 \pm 1.26$ \\
SBP $(\mathrm{mmHg})$ & $127.53 \pm 1.40$ & $123.83 \pm 1.20$ \\
Heart rate $(\mathrm{bpm})$ & $437.33 \pm 9.47$ & $431.94 \pm 7.95$ \\
\hline
\end{tabular}

${ }^{a}$ Blood pressure and heart rate were detected before MCA0. No significant differences were observed between groups. $n=4$ or 5 .

\section{OSMR $\beta$ is a positive regulator of postischemic neuronal survival}

The above-mentioned genetic manipulations of OSMR $\beta$ in vivo showed that OSMR $\beta$ function protects against I/R-induced cerebral injury. However, whether isolated primary neurons require OSMR $\beta$ for survival remained to be determined. To resolve this issue, we next performed Fluoro-Jade B, a specific marker of neurons during acute degeneration, and TUNEL staining in OSMR-KO and OSMR-TG mice $24 \mathrm{~h}$ after MCAO (Fig. $4 A$ ). OSMR $\beta$ knock-out resulted in an $\sim 2$.2-fold and 1.8-fold increase in the number of Fluoro-Jade B-positive and TUNEL-positive cells, respectively (Fig. 4B). Conversely, the number of FluoroJade B-positive cells and TUNEL-positive cells was reduced to $16.6 \%$ and $9.5 \%$, respectively, in the OSMR-TG mice (Fig. $4 B$ ). Thus, OSMR $\beta$ is critical for I/R-induced neuronal degeneration and apoptosis. Western blot analysis showed that the expression of the antiapoptotic protein Bcl-2 was decreased and that the expression levels of the proapoptotic proteins Bax, cleaved caspase-3, and cleaved caspase- 9 were increased in the WT and NTG mice $6 \mathrm{~h}$ after I/R compared with the sham controls. However, these changes were significantly attenuated in the OSMR-TG mice and enhanced in the OSMR-KO mice compared with the NTG and WT mice, respectively (Fig. $4 C$ ). Thus, these results suggest a protective role of OSMR $\beta$ against neuronal apoptosis. In light of the crucial effects of OSMR $\beta$ in vivo, we examined whether OSMR $\beta$ directly regulates neuronal survival using gain- and loss-of-function methods. To this end, we constructed an adenovirus-expressed shRNA targeting $O S M R \beta$ (i.e., AdshOSMR), which reduced OSMR $\beta$ expression by $40.7 \%$ of the scramble control levels, and an adenovirus overexpressing OSMR $\beta$ (AdOSMR), which increased OSMR $\beta$ expression by $\sim 1$.9-fold compared with the AdGFP controls (Fig. 4D). Indeed, $O S M R \beta$ overexpression (using AdOSMR) rendered neurons more resistant to OGD-induced cell death, as evidenced by their significantly increased viability and reduced LDH release. Conversely, OSMR $\beta$-silenced (using AdshOSMR) neurons were more vulnerable to OGD (Fig. $4 E, F$ ) due to the antiapoptotic effect of $O S M R \beta$, as shown by the similar temporal expression patterns of and antiapoptotic proteins that were observed between the OGD-treated primary neurons infected with $A d$ shOSMR or AdOSMR in vitro (Fig. 4G). Together, these data clearly suggest that OSMR $\beta$ protects brain tissue via its direct neuroprotective modulatory function upon stroke onset.

\section{OSMR $\beta$ activates the JAK2/STAT3 signal transduction pathway in response to ischemia/reperfusion}

Several signaling pathways, including JAK/STAT3 and MAPK, are stimulated by gp130 cytokines, although the spectrum of pathways that are activated varies depending on the cell type and the signaling effector (Richards, 2013). Notably, both pathways are crucial modulators of neuronal death/survival in ischemic cerebral injury (Shyu et al., 2008). To understand the molecular mechanism or mechanisms underlying the neuroprotective function of OSMR $\beta$, we obtained penumbral tissues from OSMR-KO and OSMR-TG mice 6 and $24 \mathrm{~h}$ after MCAO/reperfusion. Interestingly, OSMR $\beta$ did not affect the levels of MAPK family members at both time points, as evidenced by immunoblotting for total and phosphorylated ERK, JNK, and p38 (Fig. 5A). However, we observed that the JAK2/STAT3 cascade was significantly activated by OSMR $\beta$ in the setting of ischemic stroke. JAK2 and STAT3 were phosphorylated and activated 6 and $24 \mathrm{~h}$ after I/R in the WT mice; these levels were significantly reduced in the OSMR-KO mice but were further enhanced in the OSMR-TG mice compared with the WT controls (Fig. 5B). The levels of JAK2 and STAT3 phosphorylation were consistently altered in all cells subjected to OGD compared with the respective control cells, suggesting that OSMR $\beta$ activates the JAK2/STAT3 cascade but not the MAPK signaling pathway in the brain following I/R (Fig. $5 C$ ). To determine whether OSMR $\beta$ positively regulates JAK2/STAT3 activation in neurons, immunofluorescence staining for p-STAT3 and NeuN was performed on the penumbral tissues from OSMR-KO and OSMR-TG mice (Fig. 5D). Indeed, $O S M R \beta$ ablation reduced the number of $\mathrm{p}$-STAT3-positive neurons to $34.4 \%$ of that of the WT controls, and this effect was reversed for OSMR $\beta$ overexpression (Fig. $5 D$ ). Via the activation of the JAK2/STAT3 signal transduction pathway, OSMR $\beta$ translates an extracellular signal into a transcriptional response. Thus, we further validated the importance of the OSMR/JAK2/STAT3 cascade by screening its downstream targets using real-time PCR. Notably, the mRNA levels of several downstream genes involved in neuronal survival, including Bcl2, survivin, GAP-43, Reg2, Pim-1, cIAP2, and cFLIP, were positively regulated in the OSMR-KO and OSMR-TG mice compared with their respective controls (Fig. 5E). Consistent with this finding, immunoblotting showed a significant reduction in the protein levels of these effectors in the control mice following I/R; these levels were further reduced in the OSMR-KO mice but were largely restored in the OSMR-TG mice (Fig. 5F). Consistent results were observed in the in vitro OGD model (Fig. 5G). These data, together with those of our OSMR $\beta$ loss- and gain-of-function experiments in mice, suggested that OSMR $\beta$ activates the JAK2/STAT3 signal transduction pathway in response to $I / R$, thereby ameliorating ischemic lesions.

\section{OSMR $\beta$-mediated neuroprotection requires STAT3}

Although the above-mentioned data demonstrate that OSMR $\beta$ activates the JAK2/STAT3 cascade during I/R, it remained unclear whether JAK2/STAT3 is required for OSMR $\beta$-mediated protection in vivo. To resolve this issue, we first investigated whether STAT3 protects neurons by acting downstream of OSMR $\beta$ using gain- and loss-of-function approaches in vitro and in vivo. Although OSMR $\beta$ silencing (using AdshOSMR) resulted in neuronal death, as evidenced by decreased cell survival and enhanced LDH release, we observed that these effects were completely absent from neurons overexpressing STAT3 (using AdSTAT3) (Fig. 6A). Neuron-specific STAT3-TG mice were generated by crossing STAT3 flox/flox mice with CaMKII $\alpha$-Cre mice (Fig. 6B), and OSMR-KO mice were crossed with the STAT3-TG mice to generate OSMR-KO/STAT3-TG (hereafter referred to as $O K S T$ ) mice, whose genotypes were validated using immunoblotting (Fig. 6C). STAT3 overexpression in neurons reduced the infarct size to $\sim 35.3 \%$ of that of the WT control littermates (Fig. 6D). Importantly, we observed that OSMR $\beta$ deletion-mediated cerebral injury was completely ablated by joint STAT3 overexpression in neurons, as the STAT3-TG and OKST mice displayed a comparable infarct size (Fig. $6 D$ ). In addition, STAT3 overexpression completely counteracted the enhancement 


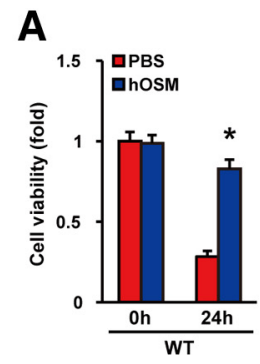

B
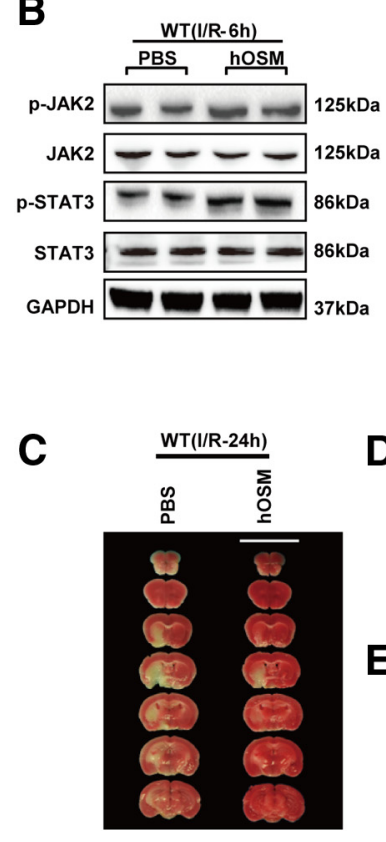
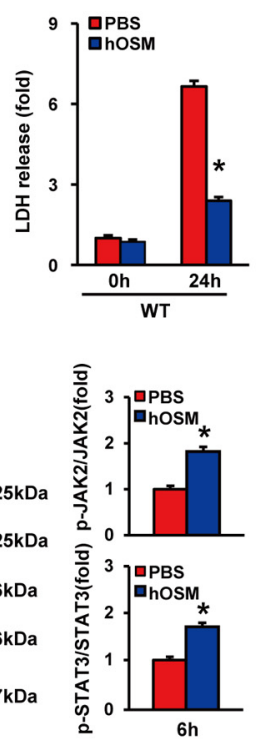

D

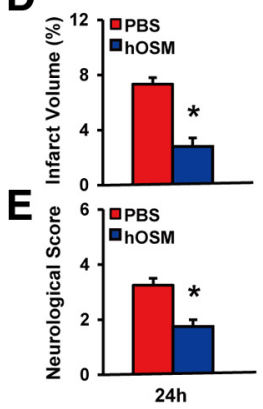

$\mathbf{F}$
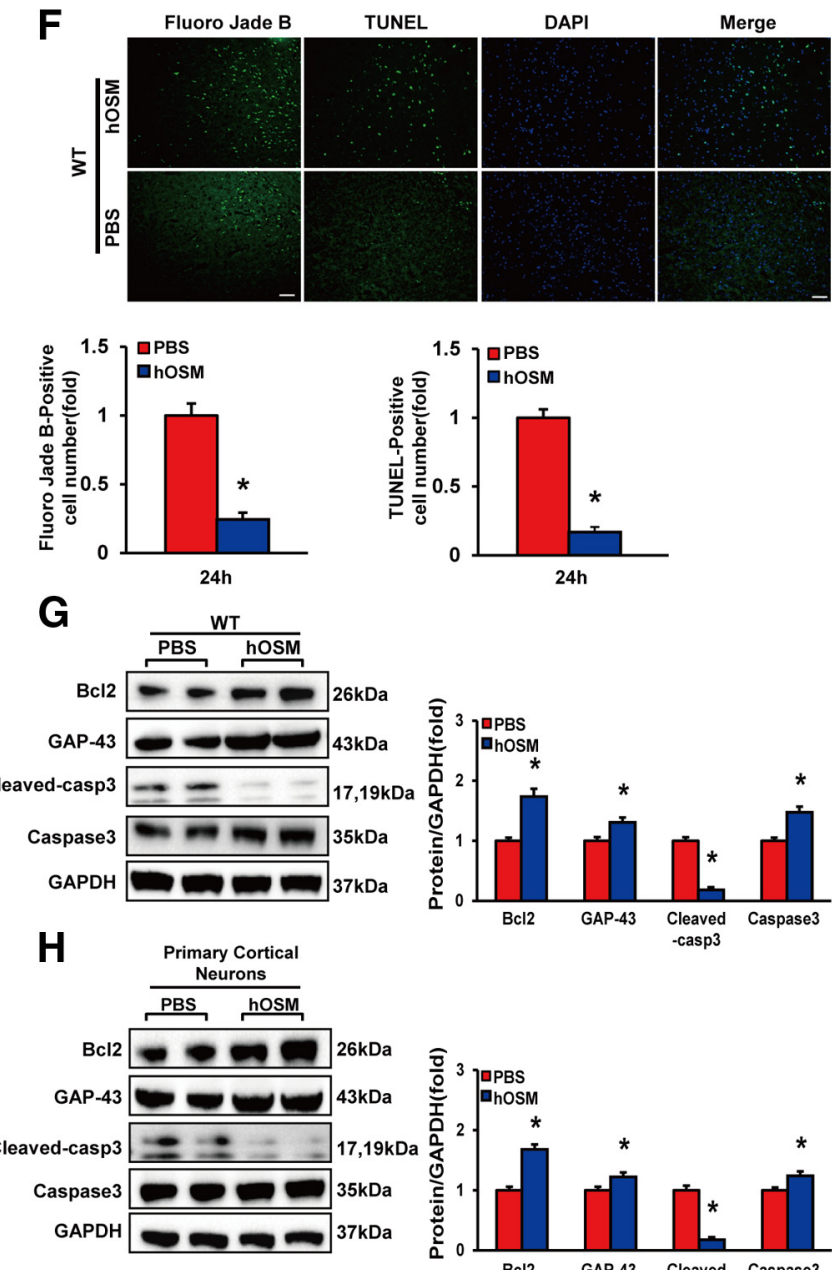
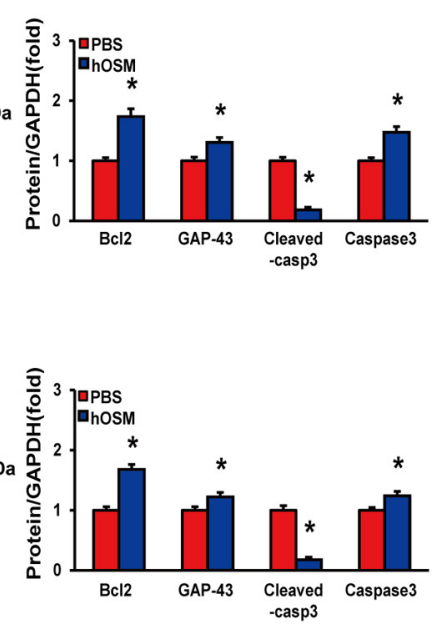

Figure 9. hOSM confers neuroprotection via JAK2/STAT3 activation. $A$, Primary neurons were isolated from WT mice and were treated with either hOSM or PBS as a control. Cell viability and LDH release assays were performed on neurons subjected to $0 \mathrm{GD}$ or the control treatment. $n=9 .{ }^{*} p<0.05$ versus the PBS control group. $\boldsymbol{B}$, Western blot analysis of total and phosphorylated JAK2 and STAT3 protein expression was performed. The results were normalized to GAPDH expression, and the expression ratios of phosphorylated JAK2 and STAT3 to the corresponding total proteins were calculated. $n=6 .{ }^{*} p<0.05$ versus the PBS control. $C-E$, hOSM administration is cerebroprotective in the absence of OSMR $\beta$. TTC staining was performed on WT mice injected with hOSM $1 \mathrm{~h}$ before $I / R(\boldsymbol{C})$. The infarct size $(\boldsymbol{D})$ and neurological deficit scores $(\boldsymbol{E})$ were quantified. $n=6$. $\boldsymbol{F}$, Fluoro-Jade $B$ and TUNEL staining were performed on WT mice injected with hOSM, and the numbers of Fluoro-Jade B-and TUNEL-positive neurons were quantified. $n=3$ or 4 . $\mathbf{G}, \boldsymbol{H}$, Western blot analysis of BCl2, cleaved caspase-3, and total caspase-3 expression in WT mice (G) or in primary neurons treated with hOSM or PBS as a control. The results were normalized to GAPDH expression, and the relative protein levels are shown. $n=6 . \boldsymbol{B}, \boldsymbol{D}-\boldsymbol{H},{ }^{*} p<0.05$ versus the PBS control. Error bars indicate mean $\pm \mathrm{SE}$.

in neuronal death caused by OSMR $\beta$ knock-out, as evidenced by the comparable number of Fluoro-Jade B- and TUNEL-positive neurons (Fig. 6E) as well as the expression levels of $\mathrm{Bcl} 2$ and cleaved caspase-3 in the STAT3-TG and OKST mice after stroke (Fig. 6F). These data suggest that STAT3 may be the most downstream target of OSMR $\beta$ in our mouse model of ischemic stroke.

To further test this hypothesis, we next investigated the protective functions of OSMR $\beta$ in the absence of STAT3. In vitro cell viability and $\mathrm{LDH}$ release assays revealed that joint infection of AdOSMR with AddnSTAT3 (to inactivate STAT3) abolished the neuroprotective effect of $O S M R \beta$ overexpression (Fig. 7A). We next crossed OSMR-TG mice with neuron-specific STAT3-KO mice to generate OSMR-TG/STAT3-KO (hereafter referred to as OTSK) mice (Fig. $7 B$ ), which we validated by immunoblotting (Fig. 7C). In the absence of STAT3, OSMR $\beta$ overexpression alone (OTSK mice) did not protect against cerebral ischemic injury, as shown by the comparable infarct sizes of the STAT3-KO and OTSK mice (Fig. 7D). Consistently, OSMR $\beta$ overexpression did not reduce neuronal death or apoptosis (Fig. $7 E$ ) or regulate ap- optotic processes (Fig. 7F) under these conditions. Based on the above-mentioned data, we concluded that OSMR $\beta$ exerts its neuroprotective function via JAK2/STAT3 signaling pathway activation in vivo.

OSM is a promising therapeutic target in rats and humans Notably, in humans and rats, OSM binds to gp130 with a limited affinity unless LIFR $\alpha$ or OSMR $\beta$ is recruited. Meanwhile, mouse OSM binds to OSMR $\beta$ but not $\operatorname{LIFR} \alpha$. Thus, using a mouse model alone does not accurately replicate human OSMR $\beta$ biological functions in vivo, an obstacle that few previous studies have been able to overcome. To address this issue, we first studied the role of OSMR $\beta$ in a rat stroke model. A time-dependent reduction in rat cerebral OSMR $\beta$ protein expression following $\mathrm{I} / \mathrm{R}$ was observed, similar to the result in mice (Fig. $8 A$ ). Consistently, neuronal OSMR $\beta$ expression was significantly decreased $24 \mathrm{~h}$ after I/R (Fig. 8B). We used the TALEN technique, which mediates gene inactivation, to generate $O S M R \beta$ knock-out rats (Fig. $8 C-F$ ), and the knock-out genotype was validated by im- 


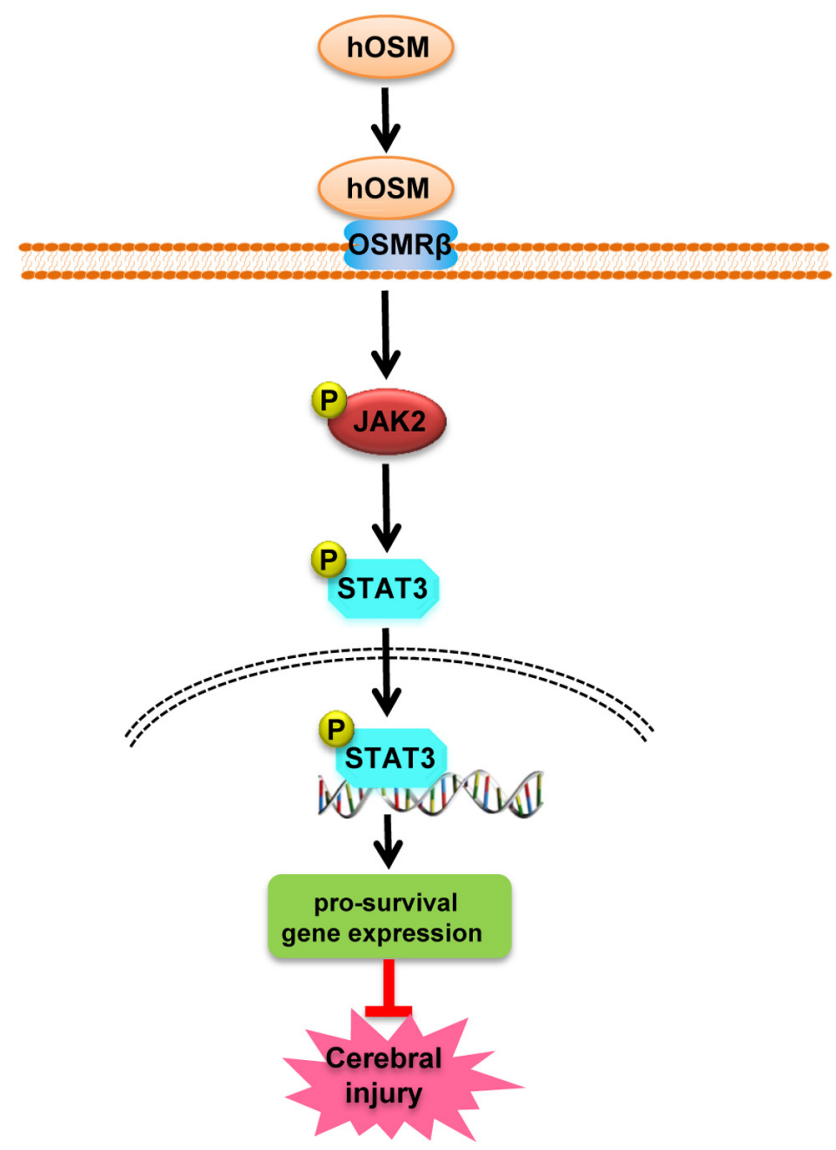

Figure 10. A working model depicting the mechanism by which OSM confers neuroprotection against ischemic stroke. Under normal conditions, OSM binds to OSMR $\beta$ at the cell surface, which sustains JAK2/STAT3 signaling pathway activation and, subsequently, neuronal survival. In response to I/R injury, however, the OSMR $\beta$ expression levels in neurons are reduced, leading to suppression of the JAK2/STAT3 prosurvival signaling pathway.

munoblotting (Fig. 8G). OSMR $\beta$ ablation had no impact on blood pressure and heart rate (Table 3 ). Consistent with the phenotype observed in mice, the OSMR ${ }^{-1-}$ rats displayed an $\sim 32.4 \%$ and $52.6 \%$ increase in infarct size 24 and $72 \mathrm{~h}$ after I/R, respectively, as well as exacerbated neurological deficits (Fig. $8 H)$. Consistent with these data, the $O S M R^{-1-}$ rats exhibited a larger infarct size than their OSMR ${ }^{+/+}$littermates (Fig. 8I). Additionally, $O S M R \beta$ deletion increased the number of Fluoro-Jade B- and TUNEL-positive neurons (Fig. $8 J$ ) by 2.0 - and 1.9-fold, respectively. The levels of the proapoptotic protein cleaved caspase- 3 and the prosurvival proteins $\mathrm{Bcl} 2$ and GAP-43 were altered in the OSMR ${ }^{-1-}$ rats compared with the controls (Fig. $8 K$ ). Importantly, the phosphorylation of JAK2/STAT3 was significantly reduced in brain homogenates (Fig. $8 L$ ) and neurons (Fig. 8M). These results indicated that OSMR $\beta$ exerts a similar neuroprotective effect in rats to that observed in mice. However, whether human OSM is involved in JAK2/STAT3 activation and neuroprotection remained unclear. Thus, we next studied the effect of hOSM in mice. Cultured primary cortical neurons treated with hOSM before OGD challenge displayed significantly attenuated cell death compared with the PBS-treated group (Fig. 9A). WT and OSMR-KO mice were administered hOSM or PBS alone $1 \mathrm{~h}$ before the performance of MCAO. Intriguingly, the hOSM-treated mice exhibited higher expression levels of phosphorylated JAK2 and STAT3 (Fig. 9B), indicating that hOSM leads to enhanced JAK2 and STAT3 activation. Next, we investi- gated whether hOSM-mediated JAK2/STAT3 activation led to neuroprotection similar to that of OSMR $\beta$ overexpression. Indeed, WT mice treated with hOSM displayed a reduced infarct size (Fig. 9C,D) and neurological deficits (Fig. 9E) as well as increased neuronal survival (Fig. $9 F$ ). In addition, the observed decrease in $\mathrm{Bcl} 2$ and GAP-43 expression and increase in cleaved caspase-3 expression were largely restored by hOSM in vivo (Fig. $9 G$ ) and in vitro (Fig. 9H). Together, these data indicated that OSM interacts with OSMR $\beta$ in response to $I / R$ and that this interaction induces the phosphorylation and activation of the JAK2/STAT3 signaling pathway. More importantly, hOSM may represent a promising therapeutic target for ischemic stroke.

\section{Discussion}

Receptors are promising therapeutic targets; indeed, $>60 \%$ of drugs approved by the FDA target cell-surface receptors (Christopoulos, 2002). Moreover, receptors, such as the glutamate NMDA and AMPA receptors, have been the most intensively investigated targets for protection against neuronal death in the setting of stroke (Besancon et al., 2008). The translation of these preclinical data into feasible medicine, however, has ended in disappointment (Savitz and Schäbitz, 2008). Although the reasons are multifactorial, these past failures are at least partially due to our insufficient understanding of the selected targets. Given the lessons learned from these failed clinical trials and given that conventional drug development largely depends on preclinical studies, it is important to gain insight into the functions of a chemotherapeutic agent in humans before advancing that agent to clinical therapy. In this study, we identified, for the first time, a critical role of hOSM in mediating neuronal survival following ischemic stroke. We established a variety of mouse and rat models of stroke that closely resembled the human condition to elucidate the effects of hOSM. Moreover, we examined the feasibility of hOSM as a potential drug to treat this fatal disease in a mouse MCAO model (Fig. 10). Our findings, which we believe are novel, are as follows: (1) OSMR $\beta$ expression was reduced in neurons after stroke; (2) a diminished OSMR $\beta$ expression level in neurons led to exacerbated cerebral damage, whereas OSMR $\beta$ overexpression protected the brain against I/R injury; (3) OSMR $\beta$ directly rescued neurons and brain tissue by activating the JAK2/STAT3 signaling pathway in neurons; and (4) hOSM sufficiently ameliorated I/R-induced brain injury. Thus, we propose that OSM may induce JAK2/STAT3-mediated neuroprotection during ischemic stroke, at least in part, by engaging neuronal OSMR $\beta$.

OSM expression is induced in inflammatory responses to stimuli, such as LPS or GM-CSF stimulation, septic shock, and overt bacterial peritonitis, although little has been known regarding OSM/OSMR $\beta$ expression in acute traumatic injury (Guillet et al., 1995; Grenier et al., 1999; Hurst et al., 2002). However, at baseline, OSMR $\beta$ mRNA is widely detected, although at a low level, in most regions of the brain, indicating the potential role of OSM/OSMR $\beta$ signaling in the CNS (Tamura et al., 2003). In addition, OSM mRNA expression increases rapidly after nerve injury, and its high expression is maintained for at least $14 \mathrm{~d}$ (Ito et al., 2000). Our study extended these findings by demonstrating that OSMR $\beta$ expression was decreased after I/R, suggesting the presence of biological functions of OSM/OSMR $\beta$ beyond those in inflammatory responses per se. Indeed, neuron-specific knock-out of OSMR $\beta$ rendered mice more vulnerable to I/Rinduced brain damage. We further showed that neurons are directly affected by OSMR $\beta$, as evidenced by the colocalization of $\mathrm{NeuN}$ and OSMR $\beta$ in vivo and by the OGD-induced downregulation of $O S M R \beta$ expression in primary cortical neurons. In line 
with our findings, OSMR $\beta$ expression was observed in a subset of neurons of murine and human DRGs (Morikawa et al., 2004). Additionally, Bando et al. (2006) performed sciatic nerve axotomy; and after $7 \mathrm{~d}$, the expression of OSMR $\beta$ was significantly downregulated in the lumbar DRGs of the injured side. We linked this reduction in neuronal OSMR $\beta$ to neuronal death, at least in response to I/R, using TUNEL and Fluoro-Jade B staining in vivo and cell viability assays in vitro. These findings were supported by a previous study by Esashi et al. (2009), who reported that OSM deficiency enhanced thymocyte apoptosis. Moreover, keratinocytes carrying mutated $O S M R \beta$ appeared to be more susceptible to apoptosis, resulting in cell death and the accumulation of degenerated keratinous material in the superficial dermis (Tanaka et al., 2010). Mechanistically, we further showed that OSMR $\beta$-mediated neuronal survival is attributable to the phosphorylation and activation of the JAK2/STAT3, but not MAPK, signaling pathway. Consistently, the activation of STAT3 has been observed in neurons and has been associated with upregulation of neuroprotective genes upon stroke (Justicia et al., 2000; Dziennis et al., 2007). However, to our knowledge, the in vivo role of STAT3 in ischemic stroke has remained poorly understood. In this study, we showed that the overexpression of STAT3 in neurons (STAT3-TG) mimicked the protective effect of OSMR $\beta$, whereas STAT3 deletion (STAT3-KO) resulted in deteriorated stroke outcomes, similar to those observed for OSMR $\beta$ deletion. Furthermore, we crossed the STAT3-TG and STAT3-KO mouse lines with OSMR-KO and OSMR-TG mice, respectively, which revealed that STAT3 activation is both necessary and sufficient to mediate OSM/ OSMR $\beta$-induced neuroprotection.

It should be noted that murine OSM engages only murine OSMR $\beta / g p 130$, which differs from that observed in humans. hOSM recruits both LIFR $\alpha$ and OSMR $\beta$ (Richards, 2013). This confounding factor is also a major problem for drug development, as species differences may alter the mechanism by which a ligand engages and activates its targets, potentially resulting in distinct pharmacological properties. For instance, ligands of the $\mathrm{H} 3$ histamine receptor act as either agonists or antagonists depending on the species expressing the receptor (Ireland-Denny et al., 2001). Interestingly, Drechsler et al. (2012) recently characterized the OSM receptor system in rats and showed that rat OSM binds to both LIFR $\alpha$ and OSMR $\beta$ in rats, as observed in humans. Thus, the OSM receptor system in rats more closely resembles the OSM receptor system in humans. Given these data, we generated a TALEN-mediated OSMR-KO rat line, which was subjected to $\mathrm{MCAO} /$ reperfusion. The OSMR-KO rats displayed a similar cerebroprotective phenotype to that of the corresponding mice, suggesting a beneficial effect of OSM/OSMR $\beta$ activation in neurons. Furthermore, although murine OSM has been shown to be neuroprotective, the role of hOSM in the setting of ischemic stroke remains unknown (Weiss et al., 2006). To address this issue, hOSM was administered to mice. Intriguingly, hOSM to a large extent preserved the viability of mouse brain tissue, indicating that hOSM may be a promising target for drug development. Nevertheless, whether LIFR $\alpha$ is also involved in OSM-mediated cerebroprotection during ischemic stroke should be further elucidated in future studies.

Together, this study shows the importance of examining species-specific ligand-receptor interactions as a strategy for future drug development and suggests that hOSM confers profound protection against ischemic stroke by activating the JAK2/ STAT3 prosurvival signaling pathway, at least partially, via recruiting OSMR $\beta$. Our findings showing that the administra- tion of hOSM rescues neurons in ischemic stroke emphasizes the potential translation of hOSM into clinical therapies for neuronal loss due to other neurological disorders, such as brain trauma, Huntington's disease, and Alzheimer's disease.

\section{References}

Albers GW, Goldstein LB, Hall D, Lesko LM (2001) Aptiganel hydrochloride in acute ischemic stroke: a randomized controlled trial. JAMA 286: 2673-2682. CrossRef Medline

Bando T, Morikawa Y, Komori T, Senba E (2006) Complete overlap of interleukin-31 receptor $\mathrm{A}$ and oncostatin $\mathrm{M}$ receptor beta in the adult dorsal root ganglia with distinct developmental expression patterns. Neuroscience 142:1263-1271. CrossRef Medline

Besancon E, Guo S, Lok J, Tymianski M, Lo EH (2008) Beyond NMDA and AMPA glutamate receptors: emerging mechanisms for ionic imbalance and cell death in stroke. Trends Pharmacol Sci 29:268-275. CrossRef Medline

Cermak T, Doyle EL, Christian M, Wang L, Zhang Y, Schmidt C, Baller JA, Somia NV, Bogdanove AJ, Voytas DF (2011) Efficient design and assembly of custom TALEN and other TAL effector-based constructs for DNA targeting. Nucleic Acids Res 39:e82. CrossRef Medline

Chen HZ, Guo S, Li ZZ, Lu Y, Jiang DS, Zhang R, Lei H, Gao L, Zhang X, Zhang Y, Wang L, Zhu LH, Xiang M, Zhou Y, Wan Q, Dong H, Liu DP, Li H (2014) A critical role for interferon regulatory factor 9 in cerebral ischemic stroke. J Neurosci 34:11897-11912. CrossRef Medline

Christopoulos A (2002) Allosteric binding sites on cell-surface receptors: novel targets for drug discovery. Nat Rev Drug Discov 1:198-210. CrossRef Medline

Drechsler J, Grötzinger J, Hermanns HM (2012) Characterization of the rat oncostatin $\mathrm{M}$ receptor complex which resembles the human, but differs from the murine cytokine receptor. PLoS One 7:e43155. CrossRef Medline

Dziennis S, Jia T, Rønnekleiv OK, Hurn PD, Alkayed NJ (2007) Role of signal transducer and activator of transcription-3 in estradiol-mediated neuroprotection. J Neurosci 27:7268-7274. CrossRef Medline

Engel O, Kolodziej S, Dirnagl U, Prinz V (2011) Modeling stroke in micemiddle cerebral artery occlusion with the filament model. J Vis Exp 47: 2423. CrossRef Medline

Ensoli F, Fiorelli V, DeCristofaro M, Santini Muratori D, Novi A, Vannelli B, Thiele CJ, Luzi G, Aiuti F (1999) Inflammatory cytokines and HIV-1associated neurodegeneration: oncostatin-M produced by mononuclear cells from HIV-1-infected individuals induces apoptosis of primary neurons. J Immunol 162:6268-6277. Medline

Esashi E, Ito H, Minehata K, Saito S, Morikawa Y, Miyajima A (2009) Oncostatin $\mathrm{M}$ deficiency leads to thymic hypoplasia, accumulation of apoptotic thymocytes and glomerulonephritis. Eur J Immunol 39:16641670. CrossRef Medline

Gazel A, Rosdy M, Bertino B, Tornier C, Sahuc F, Blumenberg M (2006) A characteristic subset of psoriasis-associated genes is induced by oncostatin-M in reconstituted epidermis. J Invest Dermatol 126:26472657. CrossRef Medline

Gearing DP, Comeau MR, Friend DJ, Gimpel SD, Thut CJ, McGourty J, Brasher KK, King JA, Gillis S, Mosley B (1992) The IL-6 signal transducer, gp130: an oncostatin M receptor and affinity converter for the LIF receptor. Science 255:1434-1437. CrossRef Medline

Grenier A, Dehoux M, Boutten A, Arce-Vicioso M, Durand G, GougerotPocidalo MA, Chollet-Martin S (1999) Oncostatin M production and regulation by human polymorphonuclear neutrophils. Blood 93:14131421. Medline

Guillet C, Fourcin M, Chevalier S, Pouplard A, Gascan H (1995) ELISA detection of circulating levels of LIF, OSM, and CNTF in septic shock. Ann N Y Acad Sci 762:407-409. CrossRef Medline

Guo S, Li ZZ, Jiang DS, Lu YY, Liu Y, Gao L, Zhang SM, Lei H, Zhu LH, Zhang XD, Liu DP, Li H (2014) IRF4 is a novel mediator for neuronal survival in ischaemic stroke. Cell Death Differ 21:888-903. CrossRef Medline

Hsu MP, Frausto R, Rose-John S, Campbell IL (2015) Analysis of IL-6/ gp130 family receptor expression reveals that in contrast to astroglia, microglia lack the oncostatin $\mathrm{M}$ receptor and functional responses to oncostatin M. Glia 63:132-141. CrossRef Medline

Hui W, Bell M, Carroll G (1997) Detection of oncostatin M in synovial fluid from patients with rheumatoid arthritis. Ann Rheum Dis 56:184-187. CrossRef Medline 
Hurst SM, McLoughlin RM, Monslow J, Owens S, Morgan L, Fuller GM, Topley N, Jones SA (2002) Secretion of oncostatin M by infiltrating neutrophils: regulation of IL-6 and chemokine expression in human mesothelial cells. J Immunol 169:5244-5251. CrossRef Medline

Ireland-Denny L, Parihar AS, Miller TR, Kang CH, Krueger KM, Esbenshade TA, Hancock AA (2001) Species-related pharmacological heterogeneity of histamine H(3) receptors. Eur J Pharmacol 433:141-150. CrossRef Medline

Ito Y, Yamamoto M, Li M, Mitsuma N, Tanaka F, Doyu M, Suzumura A, Mitsuma T, Sobue G (2000) Temporal expression of mRNAs for neuropoietic cytokines, interleukin-11 (IL-11), oncostatin M (OSM), cardiotrophin-1 (CT-1) and their receptors (IL-11Ralpha and OSMRbeta) in peripheral nerve injury. Neurochem Res 25:1113-1118. CrossRef Medline

Justicia C, Gabriel C, Planas AM (2000) Activation of the JAK/STAT pathway following transient focal cerebral ischemia: signaling through Jak1 and Stat3 in astrocytes. Glia 30:253-270. CrossRef Medline

Lees KR, Lavelle JF, Cunha L, Diener HC, Sanders EA, Tack P, Wester P (2001) Glycine antagonist (GV150526) in acute stroke: a multicentre, double-blind placebo-controlled phase II trial. Cerebrovasc Dis 11:20-29. CrossRef Medline

Li M, Guo S, Zhang P, Gong J, Zheng A, Zhang Y, Li H (2015) Vinexin-beta deficiency protects against cerebral ischaemia/reperfusion injury by inhibiting neuronal apoptosis. J Neurochem 134:211-221. CrossRef Medline

Liu Y, Wong TP, Aarts M, Rooyakkers A, Liu L, Lai TW, Wu DC, Lu J, Tymianski M, Craig AM, Wang YT (2007) NMDA receptor subunits have differential roles in mediating excitotoxic neuronal death both in vitro and in vivo. J Neurosci 27:2846-2857. CrossRef Medline

Lo EH, Dalkara T, Moskowitz MA (2003) Mechanisms, challenges and opportunities in stroke. Nat Rev Neurosci 4:399-415. CrossRef Medline

Lu YY, Li ZZ, Jiang DS, Wang L, Zhang Y, Chen K, Zhang XF, Liu Y, Fan GC, Chen Y, Yang Q, Zhou Y, Zhang XD, Liu DP, Li H (2013) TRAF1 is a critical regulator of cerebral ischaemia-reperfusion injury and neuronal death. Nat Commun 4:2852. CrossRef Medline

Morikawa Y (2005) Oncostatin M in the development of the nervous system. Anat Sci Int 80:53-59. CrossRef Medline

Morikawa Y, Tamura S, Minehata K, Donovan PJ, Miyajima A, Senba E (2004) Essential function of oncostatin $\mathrm{m}$ in nociceptive neurons of dorsal root ganglia. J Neurosci 24:1941-1947. CrossRef Medline

Moskowitz MA, Lo EH, Iadecola C (2010) The science of stroke: mechanisms in search of treatments. Neuron 67:181-198. CrossRef Medline

Oliva AA Jr, Kang Y, Sanchez-Molano J, Furones C, Atkins CM (2012) STAT3 signaling after traumatic brain injury. J Neurochem 120:710-720. CrossRef Medline
Richards CD (2013) The enigmatic cytokine oncostatin M and roles in disease. ISRN Inflamm 2013:512103. CrossRef Medline

Savitz SI, Schäbitz WR (2008) A critique of SAINT II: wishful thinking, dashed hopes, and the future of neuroprotection for acute stroke. Stroke 39:1389-1391. CrossRef Medline

Shyu WC, Lin SZ, Chiang MF, Chen DC, Su CY, Wang HJ, Liu RS, Tsai CH, $\mathrm{Li} \mathrm{H}$ (2008) Secretoneurin promotes neuroprotection and neuronal plasticity via the Jak2/Stat3 pathway in murine models of stroke. J Clin Invest 118:133-148. CrossRef Medline

Slaets H, Nelissen S, Janssens K, Vidal PM, Lemmens E, Stinissen P, Hendrix S, Hellings N (2014) Oncostatin M reduces lesion size and promotes functional recovery and neurite outgrowth after spinal cord injury. Mol Neurobiol 50:1142-1151. CrossRef Medline

Tamura S, Morikawa Y, Senba E (2003) Localization of oncostatin M receptor beta in adult and developing CNS. Neuroscience 119:991-997. CrossRef Medline

Tanaka A, Lai-Cheong JE, van den Akker PC, Nagy N, Millington G, Diercks GF, van Voorst Vader PC, Clements SE, Almaani N, Techanukul T, Hide M, South AP, McGrath JA (2010) The molecular skin pathology of familial primary localized cutaneous amyloidosis. Exp Dermatol 19:416423. CrossRef Medline

Wang L, Lu Y, Deng S, Zhang Y, Yang L, Guan Y, Matozaki T, Ohnishi H, Jiang H, Li H (2012) SHPS-1 deficiency induces robust neuroprotection against experimental stroke by attenuating oxidative stress. J Neurochem 122:834-843. CrossRef Medline

Wang L, Lu Y, Guan H, Jiang D, Guan Y, Zhang X, Nakano H, Zhou Y, Zhang Y, Yang L, Li H (2013a) Tumor necrosis factor receptor-associated factor 5 is an essential mediator of ischemic brain infarction. J Neurochem 126:400-414. CrossRef Medline

Wang L, Lu Y, Zhang X, Zhang Y, Jiang D, Dong X, Deng S, Yang L, Guan Y, Zhu L, Zhou Y, Zhang X, Li H (2013b) Mindin is a critical mediator of ischemic brain injury in an experimental stroke model. Exp Neurol 247: 506-516. CrossRef Medline

Weiss TW, Samson AL, Niego B, Daniel PB, Medcalf RL (2006) Oncostatin $\mathrm{M}$ is a neuroprotective cytokine that inhibits excitotoxic injury in vitro and in vivo. FASEB J 20:2369-2371. CrossRef Medline

Xiang M, Wang L, Guo S, Lu YY, Lei H, Jiang DS, Zhang Y, Liu Y, Zhou Y, Zhang XD, Li H (2014) Interferon regulatory factor 8 protects against cerebral ischaemic-reperfusion injury. J Neurochem 129:988-1001. CrossRef Medline

Zhang C, Li H, Liu MG, Kawasaki A, Fu XY, Barnstable CJ, Shao-Min Zhang S (2008) STAT3 activation protects retinal ganglion cell layer neurons in response to stress. Exp Eye Res 86:991-997. CrossRef Medline 